\title{
Microstructural Effects of Sulphate Attack in Sustainable Grouts for Micropiles
}

\author{
José Marcos Ortega Álvarez ${ }^{1,2, *}$, María Dolores Esteban Pérez ${ }^{2}$, \\ Raúl Rubén Rodríguez Escribano ${ }^{2}$, José Luís Pastor Navarro ${ }^{1}$ and Isidro Sánchez Martín ${ }^{1}$ \\ 1 Departamento de Ingeniería Civil, Universidad de Alicante, Ap. Correos 99, 03080 Alacant/Alicante, Spain; \\ joseluis.pastor@ua.es (J.L.P.N.); isidro.sanchez@ua.es (I.S.M.) \\ 2 Departamento de Ingeniería Civil, Urbanismo y Aeroespacial, Escuela de Arquitectura, Ingeniería y Diseño, \\ Universidad Europea, c/Tajo s/n, 28670 Villaviciosa de Odón, Spain; \\ mariadolores.esteban@universidadeuropea.es (M.D.E.P.); \\ raulruben.rodriguez@universidadeuropea.es (R.R.R.E.) \\ * Correspondence: jm.ortega@ua.es; Tel.: +34-96-5903-400 (ext. 1167) \\ Academic Editor: Claudio Ferone \\ Received: 30 August 2016; Accepted: 28 October 2016; Published: 8 November 2016
}

\begin{abstract}
Nowadays, the use of micropiles has undergone a great development. In general, they are made with cement grout, reinforced with steel tubing. In Spain, these grouts are prepared using OPC, although the standards do not forbid the use of other cements, like sustainable ones. Micropiles are in contact with soils and groundwater, in which the presence of sulphates is common. Their deleterious effects firstly affect to the microstructure. Then, the aim of this research is to study the effects of sulphate attack in the microstructure of micropiles grouts, prepared with OPC, fly ash and slag commercial cements, compared to their behaviour when they are exposed to an optimum hardening condition. The microstructure evolution has been studied with the non-destructive impedance spectroscopy technique, which has never been used for detecting the effects of sulphate attack when slag and fly ash cements are used. Its results have been contrasted with mercury intrusion porosimetry and "Wenner" resistivity ones. The 28-day compressive strength of grouts has been also determined. The results of microstructure characterization techniques are in agreement, although impedance spectroscopy is the most sensitive for following the changes in the porous network of grouts. The results showed that micropiles made using fly ash and slag cements could have a good performance in contact with aggressive sodium sulphate media, even better than OPC ones.
\end{abstract}

Keywords: micropiles; special geotechnical works; impedance spectroscopy; microstructure; fly ash; ground granulated blast furnace slag; sulphate attack; cement grouts

\section{Introduction}

In recent years, special geotechnical works have undergone a great development, becoming essential tools thatallow solving engineering problems, mainly related to interaction between the structures and terrain. One of the most used special geotechnical works are micropiles. They have many advantages, such as adaptability to all kind of terrains [1,2]. For this reason, micropiles are used for underpinning existing foundations, supporting the crown of tunnels and stabilizing slopes and excavations, among other applications [1,2]. Micropiles are small-diameter piles with diameters under $300 \mathrm{~mm}$, drilled and grouted with cement grout or mortar, reinforced with steel tubing and sometimes strengthened with one or several ribbed bars [1]. The micropiles standards [3,4] do not specify the cement type to use, provided that it reaches a certain compressive strength.

However, at least in Spain, generally the cement grouts for micropiles are usually prepared using an ordinary Portland cement, despite no existing specific restriction for preparing these grouts with 
other types of cements, like sustainable ones. These sustainable cements in most cases contain active additions, like fly ash and ground granulated blast furnace slag. The use of these cements shows many advantages [5-9]. On the one hand, these cements contribute to reduce $\mathrm{CO}_{2}$ emissions produced by the cement industry, because the additions replace a proportion of clinker, so less quantity of this product is needed. Furthermore, the most used active additions are wastes of other industrial processes, and their reuse in cement manufacture constitutes in itself an environmental benefit. On the other hand, the most common active additions improve the properties of cement-based materials and their effects are still now a topic of study [5,10-12]. Among the different active additions, in this research cements that incorporate fly ash and ground granulated blast furnace slag have been studied. Regarding blast furnace slag, the development of their hydration reactions entails the formation of additional CSH phases, increasing the microstructure refinement [13], which improves the service properties of cement-based materials $[14,15]$. On the other hand, fly ash has a similar effect in the microstructure and properties of these materials, although this admixture is able to react with portlandite [11], which is formed during the clinker hydration. As products of these pozzolanic reactions, new hydrated phases are produced, which densify the pore network of the material $[5,11]$. Therefore, both additions have good performance for many applications [5], particularly for marine structures [7,16-18]. Despite that, cements containing fly ash or slag are not used for making cement grouts for micropiles.

With respect to the durability of micropiles, it is important to emphasize the abovementioned fact that the reinforcement elements of this type of special foundation are embedded in cement grouts (pastes), instead of concrete, as happens in the majority of civil engineering structures. Then, it could entail a different behaviour of these elements against the attack of aggressive substances, especially if sustainable cements are used.

One of the most important aggressive attacks to which micropiles can be exposed is that produced by sulphate, because this aggressive is commonly present in soils and groundwater. The sulphate attack is produced by a complex mechanism, which involves different chemical reactions between components of cement paste microstructure and sulphate ions [19]. First of all, the effect of sulphate attack produces a gradual dissolution of portlandite and decomposition of the CSH phases $[19,20]$ and whenever the attack is being developing, more and more ettringite crystals are formed in the pore network [21]. These crystals are expansive, and when the pores are filled enough, they start to cause volumetric strains in the hardened material, which brings microcracking and a loss of pore refinement [20,22]. Moreover, as consequence of those damages in the microstructure, it is also produced a loss of strength and durability in the cement-based materials exposed to sulphate attack [22]. In relation to mineral admixtures, several studies have shown that they reduce the degree of damage produced by sulphate attack [19,23-25]. In general, this better behaviour has been related to the higher microstructure refinement, less C3A availability and additional formation of CSH phases $[19,25]$ produced by the addition of fly ash and slag. Besides, for fly ash cements, the lower presence of portlandite due to their consumption during pozzolanic reactions $[19,26]$ also favours their better sulphate resistance. Nevertheless, it has been observed that the performance against sulphate attack of sustainable cements depends on the kind of active addition used, and the degree of substitution of clinker by admixture [25,27-32].

As has been previously mentioned, the microstructure of cement-based materials is directly related to their service properties [13,33], especially their durability. Nowadays, the use of non-destructive techniques for characterizing the microstructure of cement-based materials has become an important research field [34-39]. Among these techniques, impedance spectroscopy has experienced a great development during the last years. This technique is based on the possibility of correlating dielectric and mechanical properties of a solid material [40]. Recently, impedance spectroscopy has been successfully used for studying the microstructure of cement-based materials [41-45], although there is no experience of using this technique for detecting the effects of sulphate attack when cements which incorporate fly ash and slag are used. However, it has been demonstrated that impedance spectroscopy can be useful for detecting the appearance of microcracking [45]. One of the effects of the expansive 
forces produced by the formation of ettringite crystals is microcracking, as has been already explained, so it seems that this technique could be useful in the context of this research.

Therefore, the main objective of this research is to study the effects of sulphate attack in the microstructure of sustainable grouts for micropiles, prepared with fly ash and slag commercial cements, compared to their behaviour when they are exposed to an optimum hardening condition. Moreover, for both conditions OPC grouts have also been studied. The evolution of the microstructure has been studied using non-destructive impedance spectroscopy technique. In order to check the validity of their results, they have been contrasted with those obtained using the classical destructive technique of mercury intrusion porosimetry and the well-known non-destructive "Wenner" resistivity test. Finally, 28-day compressive strength of grouts has also been determined, because it is the main parameter established by micropiles standards $[3,46,47]$ for validating the grouts, and in addition to this, it is a commonly used parameter in literature for analysing the performance of cement-based materials against sulphate attack $[19,48-50]$.

\section{Materials and Methods}

\subsection{Sample Preparation}

Cement grouts (pastes) were studied in this research. Three different commercial cements were used for preparing the grouts. The first one was an ordinary Portland cement, designated CEM I 42.5 R (CEM I hereafter) according to the Spanish and European standard UNE-EN 197-1 [4]. Moreover, the grouts were also made with two cements which contribute to sustainability, a type III/B 42.5 L/SR [4] (CEM III from now on), with a content of ground granulated blast-furnace slag between $66 \%$ and $80 \%$ of total binder), and a fly ash cement, type CEM IV /B(V) $32.5 \mathrm{~N}$ [4] (labelled CEM IV hereafter), whose content of addition was between $36 \%$ and $55 \%$ of total binder. The use of commercial cements is focused on approaching to in situ conditions of micropiles construction, where it would be very difficult to prepare mixes of ordinary Portland cement and the corresponding active addition for grouting these elements. For all the grouts, the selected water to cement ratio was 0.5 , which achieves the requirements of micropiles standard [3] related to this parameter, according to the results obtained in previous researches of the authors [51-53], in which similar grouts were characterized in depth. The mix proportions of the grouts per cubic meter are shown in Table 1.

Table 1. Mix proportions of the grouts per cubic meter.

\begin{tabular}{cc}
\hline Element & $\mathbf{K g} / \mathbf{m}^{\mathbf{3}}$ \\
\hline Cement & 1270 \\
Distilled water & 635 \\
\hline
\end{tabular}

Different types of specimens were prepared. On the one hand, three kinds of cylindrical specimens were made. They were cast in moulds of $10 \mathrm{~cm}$ diameter and $15 \mathrm{~cm}$ height and in moulds of $30 \mathrm{~cm}$ height and $7.5 \mathrm{~cm}$ or $15 \mathrm{~cm}$ diameter, respectively. On the other hand, prismatic specimens with dimensions $4 \mathrm{~cm} \times 4 \mathrm{~cm} \times 16 \mathrm{~cm}$ were also made [54]. All the samples were cured for 7 days in a temperature and humidity controlled chamber at $20{ }^{\circ} \mathrm{C}$ and $95 \% \mathrm{RH}$, and, following this period, de-moulded and introduced into the corresponding exposure medium. Before being exposed to the hardening media, $15 \mathrm{~cm}$-height cylindrical samples were cut to obtain two kinds of disks of approximately 1 and $2 \mathrm{~cm}$ thickness. The different samples used for each technique and exposure media are summarized in Table 2. 
Table 2. Samples used for each technique and exposure media.

\begin{tabular}{|c|c|c|c|c|c|}
\hline Technique & Exposure Medium & Type of Sample & Exposure Time & $\begin{array}{l}\text { Samples } \\
\text { Tested }\end{array}$ & Standard \\
\hline \multirow{2}{*}{$\begin{array}{l}\text { Impedance } \\
\text { spectroscopy }\end{array}$} & 15 wt $\% \mathrm{Na}_{2} \mathrm{SO}_{4}$ & $\begin{array}{l}\text { Disks } 10 \mathrm{~cm} \text { diameter and } \\
2 \mathrm{~cm} \text { thickness }\end{array}$ & Up to 120 days & 5 & $\mathrm{n} / \mathrm{a}$ \\
\hline & Distilled water & $\begin{array}{l}\text { Disks } 10 \mathrm{~cm} \text { diameter and } \\
1 \mathrm{~cm} \text { thickness }\end{array}$ & Up to 90 days & 5 & $\mathrm{n} / \mathrm{a}$ \\
\hline \multirow{2}{*}{$\begin{array}{l}\text { Electrical } \\
\text { resistivity }\end{array}$} & 15 wt $\% \mathrm{Na}_{2} \mathrm{SO}_{4}$ & $\begin{array}{c}\text { Cylinders } 30 \mathrm{~cm} \text { height and } \\
7.5 \mathrm{~cm} \text { diameter }\end{array}$ & Up to 120 days & 4 & UNE 83988-2 \\
\hline & Distilled water & $\begin{array}{c}\text { Cylinders } 30 \mathrm{~cm} \text { height and } \\
15 \mathrm{~cm} \text { diameter }\end{array}$ & Up to 90 days & 4 & UNE 83988-2 \\
\hline \multirow{2}{*}{$\begin{array}{l}\text { Mercury } \\
\text { intrusion } \\
\text { porosimetry }\end{array}$} & 15 wt $\% \mathrm{Na}_{2} \mathrm{SO}_{4}$ & $\begin{array}{c}\text { Pieces of disks } 10 \mathrm{~cm} \\
\text { diameter and } 2 \mathrm{~cm} \text { thickness }\end{array}$ & $28,60,90$ and 120 days & 2 & $\mathrm{n} / \mathrm{a}$ \\
\hline & Distilled water & $\begin{array}{c}\text { Pieces of disks } 10 \mathrm{~cm} \\
\text { diameter and } 1 \mathrm{~cm} \text { thickness }\end{array}$ & 2,28 and 90 days & 2 & $\mathrm{n} / \mathrm{a}$ \\
\hline \multirow{2}{*}{$\begin{array}{l}\text { Compressive } \\
\text { strength }\end{array}$} & 15 wt $\% \mathrm{Na}_{2} \mathrm{SO}_{4}$ & Prisms $4 \mathrm{~cm} \times 4 \mathrm{~cm} \times 16 \mathrm{~cm}$ & 28 days & 3 & UNE-EN 196-1 \\
\hline & Distilled water & Prisms $4 \mathrm{~cm} \times 4 \mathrm{~cm} \times 16 \mathrm{~cm}$ & 28 days & 3 & UNE-EN 196-1 \\
\hline
\end{tabular}

\subsection{Exposure Media}

When the curing period had finished, all specimens were exposed to two different media. The first one was a solution which contained a $15 \%$ by weight of reagent grade anhydrous sodium sulphate $\left(\mathrm{Na}_{2} \mathrm{SO}_{4}\right)$ in order to study the behaviour of grouts regarding the attack of this aggressive. The second medium consisted in submerging the samples in distilled water until the testing age. This last condition has been used as a reference for comparing the effects of sulphate attack to an optimum hardening condition.

With respect to the type of specimens put in contact with each medium, the $1 \mathrm{~cm}$-thickness and $10 \mathrm{~cm}$-diameter disks and the $30 \mathrm{~cm}$-height and $15 \mathrm{~cm}$-diameter cylinders were kept in distilled water, while the $2 \mathrm{~cm}$-thickness disks and $7.5 \mathrm{~cm}$-diameter cylinders were exposed to $\mathrm{Na}_{2} \mathrm{SO}_{4}$ solution. Finally, prismatic samples were used for both conditions.

For specimens immersed in distilled water, the tests were performed at different ages until 90 days, and in the case of specimens submerged in sodium sulphate solution, the maximum testing age was 120 days. This is due to the fact that it is considered that after 90 hardening days exposed to an optimum laboratory condition, like distilled water, the majority of the clinker hydration has been developed [11,55], so the microstructure would be mature enough. Furthermore, with respect to sustainable cements, 90 days is also an adequate target age for evaluating the pozzolanic activity of active additions [11]. On the other hand, in order to observe more effects of sulphate attack on grouts, which could be still relatively low at 90 days of exposure [56-58], despite the moderately high content of aggressive in the medium, the study time for this medium was extended until 120 days. The sodium sulphate solution was changed once during the test period, after 60 days exposure.

Finally, for both conditions, the volume of distilled water or sulphate solution was approximately 4 times the volume of the samples, as recommend the ASTM C 1012-04 standard [59].

\subsection{Impedance Spectroscopy}

Impedance spectroscopy is a non-destructive technique, which permits to follow the evolution of the microstructure of the same sample during the study period. Moreover, this technique allows obtaining global information of the microstructure of the sample, which is an important advantage compared to other classical techniques, like mercury intrusion porosimetry. Impedance spectroscopy has been mainly used for studying the pore structure of ordinary Portland cement-based materials [43,60], although several researches [45,61] have been recently published in which the microstructure evolution of samples with active additions has been followed with this technique. Nevertheless, there is no experience about using impedance spectroscopy for studying slag and fly ash cement samples exposed to sulphate attack. 
The impedance analyser used for performing the measurements on cement grouts was an Agilent 4294A (Agilent Technologies, Kobe, Japan). This analyser allows capacitance measurements in the range from $10^{-14} \mathrm{~F}$ to $0.1 \mathrm{~F}$, and its maximum resolution is $10^{-15} \mathrm{~F}$. For all measurements, the electrodes used were circular $(\varnothing=8 \mathrm{~cm})$ and made of flexible graphite, attached to a copper piece with the same diameter, and the frequencies for obtaining the impedance spectra ranged between $100 \mathrm{~Hz}$ and $100 \mathrm{MHz}$.

Two measurement methods were used. The first one was a contacting method, being the electrode in direct contact with the sample. The second method consisted in a non-contacting one, in which a polyester sheet (100 $\mu \mathrm{m}$ thick) was placed between the sample and each electrode. This method allows reducing the possible contributions of the sample-electrode interface [62] and it also allows minimizing the runaway capacitance existing due to the border effect [43]. In the non-contacting method, the impedance of the polyester sheets is subtracted from the total impedance measurement, to get only the impedance response of the specimen. Finally, the answer of the specimen is transformed to a spectrum in capacities using the Cole-Cole transformation [60], as this method gives an almost capacitive impedance spectrum.

The measurements were validated using the Kramers-Kronig (K-K) [63] (see Figure 1) and the differential impedance analysis was applied to them, in order to check the validity of equivalent circuit used $[46,61,64]$. The impedance spectra were fitted to the equivalent circuits proposed by Cabeza et al. [60] (see Figure 1), which included two time constants and have been used for different types of materials $[43,46,61]$. The fitting of the measured data to the equivalent circuits has been made using a Simplex optimization method [62]. The impedance parameters $R_{2}, C_{1}$ and $C_{2}$ are present in both contacting and non-contacting methods. Here, only the values of these parameters obtained with non-contacting method have been studied, due to its higher accuracy.

(a)

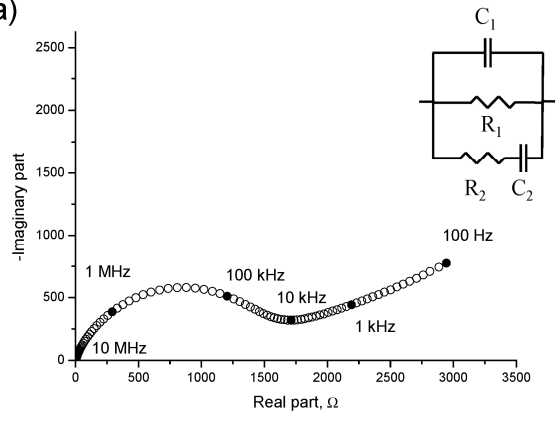

(c)

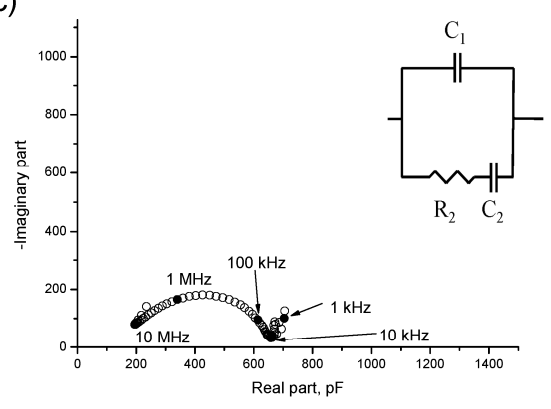

(b)

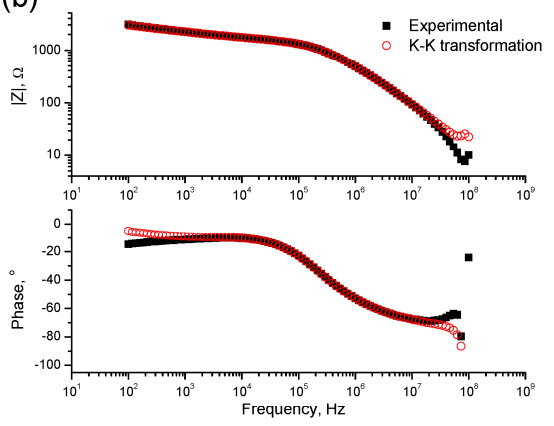

(d)

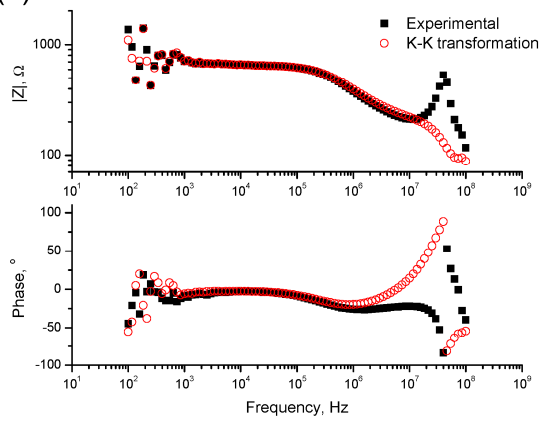

Figure 1. (a) Nyquist plot obtained for a CEM IV grout at 30 days of exposure to sodium sulphate solution and the equivalent circuit used for the fitting of the impedance spectra obtained using the contacting method [60]; (b) Bode plot for the same CEM IV grout validated using the Kramers-Kronig $(\mathrm{K}-\mathrm{K})$ relations (see the text for details); (c) Cole-Cole plot for a CEM III grout after being immersed in sodium sulphate solution during 40 days and the equivalent used for the fitting of the impedance spectra obtained using the non-contacting method [60]; and (d) Bode plot for the abovementioned CEM III grout validated using the Kramers-Kronig $(\mathrm{K}-\mathrm{K})$ relations. 
For each cement type and exposure medium, five different samples were tested. The specimens were $10 \mathrm{~cm}$-diameter disks with $1 \mathrm{~cm}$ of thickness for distilled water medium and with $2 \mathrm{~cm}$ of height in the case sodium sulphate solution. Since the thickness of the samples is not the same, the results of impedance spectroscopy cannot be directly compared. A normalization procedure already described $[43,65]$ is necessary to establish a comparison of the evolution of the dielectric parameters as a function of the solution where samples were kept.

\subsection{Electrical Resistivity}

The electrical resistivity of the grouts was determined using the Wenner four-point test, according to the Spanish standard UNE 83988-2 [66]. This is a well-known non-destructive technique which gives information about microstructure and pore connectivity in a material $[67,68]$. In this research, electrical resistivity was measured on $30 \mathrm{~cm}$-height with $7.5 \mathrm{~cm}$ - (sodium sulphate solution) and $15 \mathrm{~cm}$-diameter (distilled water) cylinders using a Proceqanalyser.

\subsection{Mercury Intrusion Porosimetry}

In order to check the results of abovementioned non-destructing techniques, the microstructure of the grouts was also characterized using the classical mercury intrusion porosimetry, despite its drawbacks [69,70]. The tests were performed with a porosimeter model Autopore IV 9500 from Micromeritics (Norcross, GA, USA), which allows determining pore diameters between $5 \mathrm{~nm}$ and $0.9 \mathrm{~mm}$. Before the test, samples were oven dried for $48 \mathrm{~h}$ at $50{ }^{\circ} \mathrm{C}$. For each testing age, two measurements were made on each material, and the samples were obtained from disks of $1 \mathrm{~cm}$ and $2 \mathrm{~cm}$-thickness. Total porosity, pore size distribution and percentage of $\mathrm{Hg}$ retained at the end of the experiment were studied. For specimens immersed in distilled water the tests were performed at 2 , 28 and 90 days of age, and for those exposed to sodium sulphate solution the testing ages were 28,60 , 90 and 120 days.

\subsection{Compressive Strength}

The compressive strength of the grouts is an important parameter because micropiles standard [3] establishes specific strength requirements which the grouts have to achieve. Furthermore, compressive strength is very commonly used in the literature $[19,27,71]$ for analysing the effect of sulphate media on the behaviour of cement-based materials. The compressive strength was measured according to the Spanish standard UNE-EN 196-1 [54], using prismatic specimens $4 \mathrm{~cm}$ square $\times 16 \mathrm{~cm}$ deep. For each cement type and exposure medium, three samples were tested. The compressive strength was determined at 28 days of age.

\section{Results}

\subsection{Impedance Spectroscopy}

The evolution of resistance $\mathrm{R}_{1}$ for grouts exposed to $15 \% \mathrm{Na}_{2} \mathrm{SO}_{4}$ solution and distilled water is depicted in Figure 2. Firstly, for samples immersed in sodium sulphate solution, it has been observed an initial increasing tendency of this parameter, although it decreased at greater ages. However, the abovementioned later fall was produced at different ages depending on the cement type used for preparing the grouts. For CEM I and III samples, the resistance $\mathrm{R}_{1}$ started reducing at 70 days of exposure approximately, and for CEM IV ones this resistance decreased after 110 days. In general, the $R_{1}$ values were higher for samples with active additions. The rise of this parameter is delayed for CEM IV grouts, as consequence, until 40 days the resistance $R_{1}$ was very similar for CEM I and III samples, with greater values than CEM IV ones. From then to 80 days approximately, CEM III grouts showed the highest $R_{1}$ values, besides at 60 exposure days, the CEM IV grouts resistance $R_{1}$ started rising and it overtook quickly the CEM I $R_{1}$ values. Finally, from 80 days the greatest $R_{1}$ were 
observed for CEM IV grouts, until the great fall produced at 110 days, showing similar values to CEM III samples thereafter.

In relation to the grouts submerged in distilled water during their hardening (Figure 2), the resistance $R_{1}$ rose with time for all of them, and this parameter was higher for CEM III samples followed by CEM IV ones, so their lowest values corresponded to those prepared using CEM I. The $R_{1}$ values were greater for grouts exposed to sodium sulphate solution than for those immersed in distilled water, which is due to the different conductivity of both media, as a consequence only the tendencies of this parameter can be compared, not their absolute values.

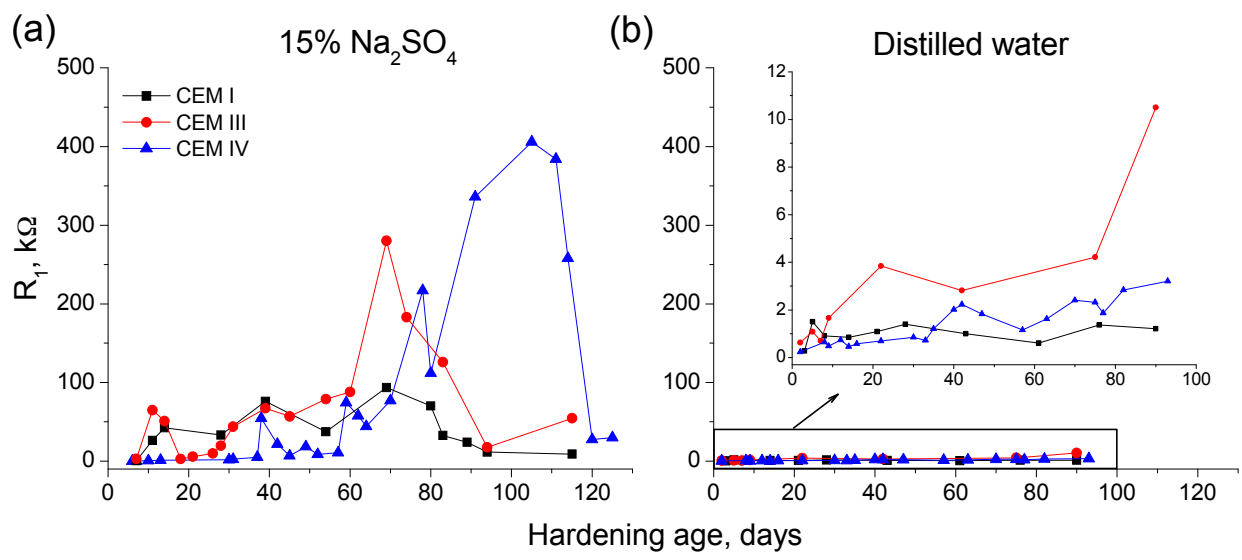

Figure 2. Evolution of impedance spectroscopy resistance $\mathrm{R}_{1}$ for CEM I, III and IV grouts exposed to: $15 \% \mathrm{Na}_{2} \mathrm{SO}_{4}$ solution (a); and distilled water (b).

The resistance $\mathrm{R}_{2}$ results for grouts hardened in contact with sulphate solution and distilled water are shown in Figure 3. In general, the tendencies observed for this parameter were very similar than those observed for resistance $R_{1}$. The resistance $R_{2}$ increased in the short-term for samples immersed in $15 \% \mathrm{Na}_{2} \mathrm{SO}_{4}$ solution and it decreased at greater ages, although this late fall was less noticeable than that noted for resistance $R_{1}$. The rise of $R_{2}$ parameter was also slower for CEM IV grouts, as happened for $R_{1}$. The $R_{2}$ values were higher for grouts that incorporated active additions, in the short-term the greatest $R_{2}$ corresponded to CEM III samples and in the long-term CEM IV ones showed the highest values of this impedance parameter.

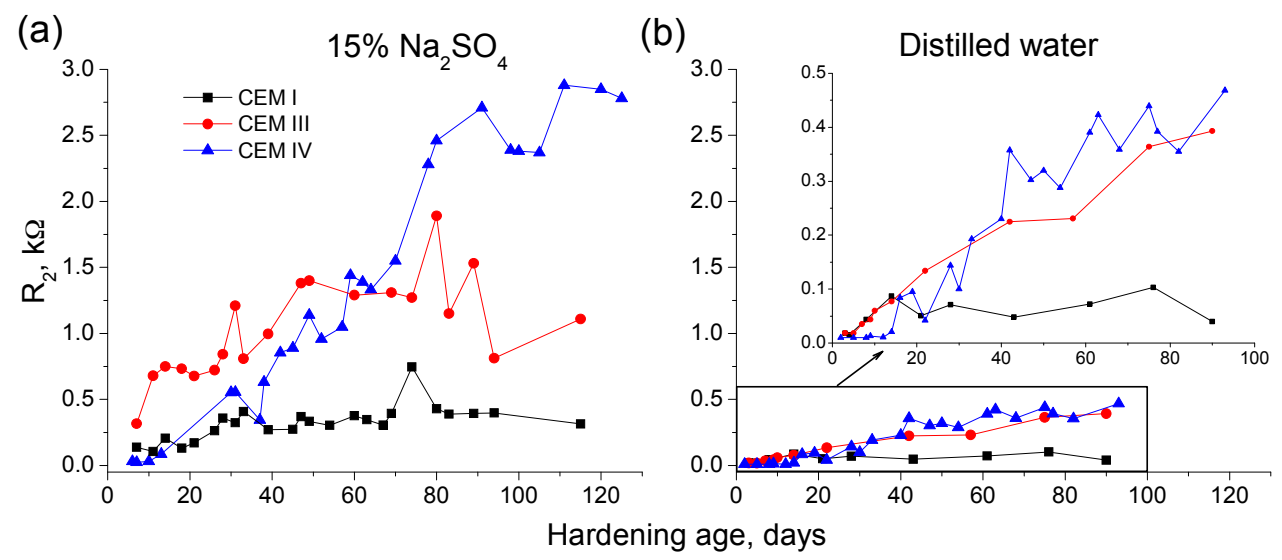

Figure 3. Results of resistance $\mathrm{R}_{2}$ for CEM I, III and IV grouts submerged in: $15 \% \mathrm{Na}_{2} \mathrm{SO}_{4}$ solution (a); and distilled water $(\mathbf{b})$.

The grouts with active additions kept in distilled water experienced an increase with time of resistance $R_{2}$ without falling in the long-term (Figure 3), which is in accordance with $R_{1}$ results, and, 
for CEM I ones, it kept practically constant. The highest $R_{2}$ values have been observed for fly ash and slag grouts. Lastly, as it has been previously mentioned for $R_{1}$ results, the absolute values of resistance $R_{2}$ cannot be also compared between the both media studied, because they are influenced by their different conductivity.

The next impedance parameter results to describe are the capacitance $C_{1}$ ones, which can be observed in Figure 4 for samples exposed to sodium sulphate solution. For all cement types studied, capacitance $C_{1}$ showed a similar increasing tendency since early ages until it reached a maximum value, when it started decreasing. The exposure age needed for achieving this maximum depended on the cement type, for CEM I this age was 50 days approximately and it was delayed until 60 and 110 days for CEM III and IV grouts, respectively. In spite of that, in general terms, there was not a great difference between the capacitance $C_{1}$ results obtained for the different grouts studied.

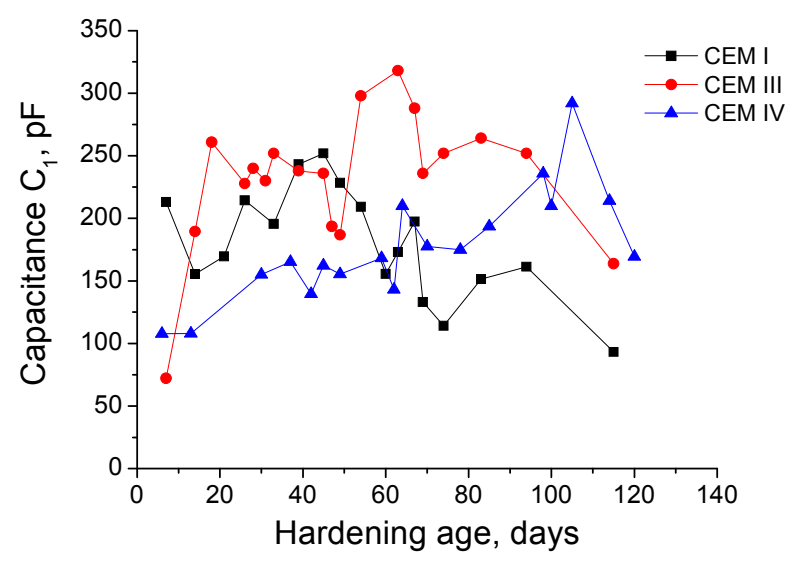

Figure 4. Impedance parameter $\mathrm{C}_{1}$ results for CEM I, CEM III and CEM IV grouts maintained in a $15 \% \mathrm{Na}_{2} \mathrm{SO}_{4}$ solution.

The evolution of capacitance $C_{1}$ of the grouts was different depending on the hardening condition, as can be observed in Figure 5. In relation to CEM I grouts, this parameter kept practically constant for those immersed in distilled water, which contrasted with the previously mentioned initial rise and the later decrease of capacitance $\mathrm{C}_{1}$ observed for CEM I grouts exposed to $15 \% \mathrm{Na}_{2} \mathrm{SO}_{4}$ solution. Moreover, in general, the $\mathrm{C}_{1}$ values were higher for CEM I grouts in contact with sodium sulphate solution than for those kept in distilled water. The capacitance $C_{1}$ for CEM III grouts was also greater for samples immersed in sulphate solution, however the changes with age of this parameter were more noticeable than those observed for CEM III grouts hardened in distilled water. In the short-term, the capacitance $C_{1}$ was very similar for CEM IV samples, independently of exposure environment, and since 40 days this parameter was higher for those submerged in $15 \% \mathrm{Na}_{2} \mathrm{SO}_{4}$ solution.

The results of capacitance $C_{2}$ for grouts kept immersed in sodium sulphate solution are shown in Figure 6. At early ages, this capacitance grew for the three types of grouts studied but in the long-term, it decreased for all of them, reaching similar values than the initial ones for each grout type. The highest capacitance $\mathrm{C}_{2}$ values corresponded to CEM III samples and the lowest were for CEM I ones.

For each cement type, the comparison between the capacitance $C_{2}$ results obtained for grouts immersed in sodium sulphate solution and distilled water is represented in Figure 7. For CEM I samples hardened in distilled water, the capacitance $\mathrm{C}_{2}$ increased with time without falling at higher ages, as happened with those exposed to $15 \% \mathrm{Na}_{2} \mathrm{SO}_{4}$ solution. The behaviour of CEM III and IV grouts regarding capacitance $\mathrm{C}_{2}$ was very similar than that previously described for CEM I ones, and the highest values of this parameter havebeen observed for samples immersed in distilled water. 

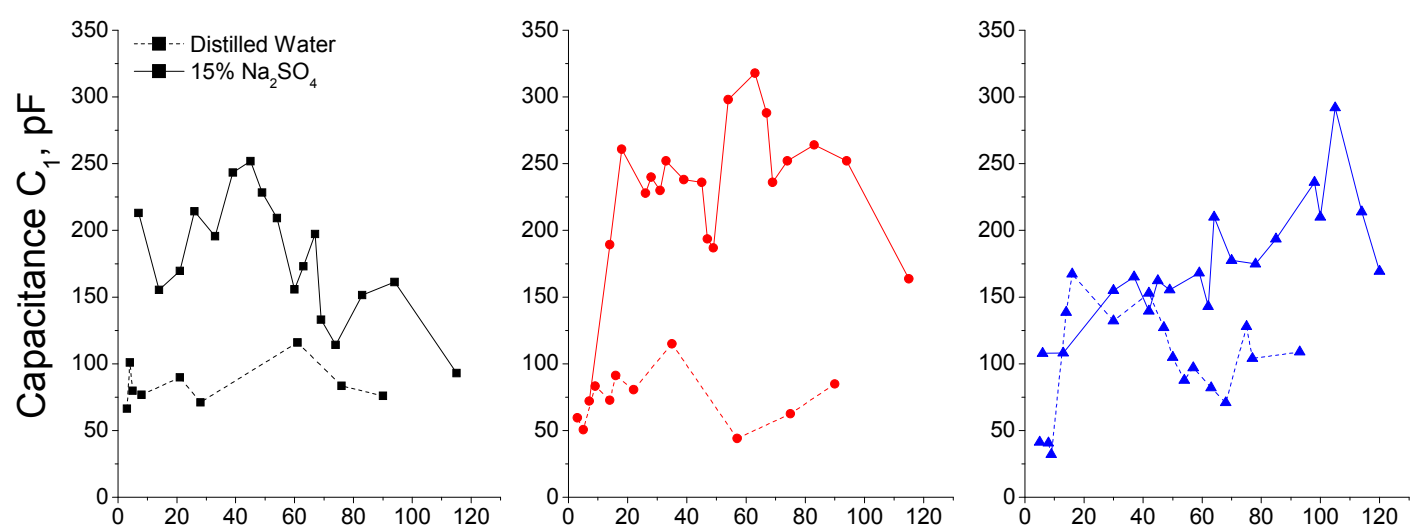

Hardening age, days

Figure 5. Comparison of capacitance $\mathrm{C}_{1}$ values obtained for CEM I, CEM III and CEM IV grouts kept in contact with distilled water (dotted line) and $15 \% \mathrm{Na}_{2} \mathrm{SO}_{4}$ solution (continuous line).

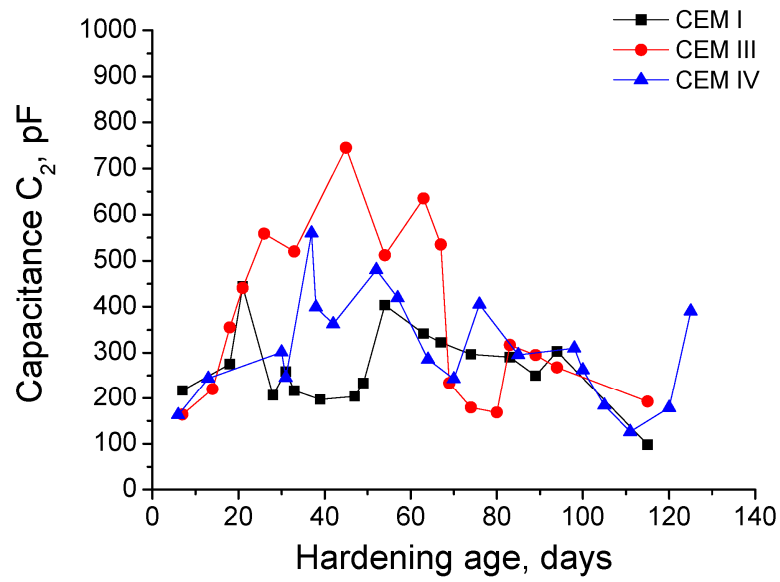

Figure 6. Results of capacitance $\mathrm{C}_{2}$ for CEM I, CEM III and CEM IV grouts exposed to 15\% $\mathrm{Na}_{2} \mathrm{SO}_{4}$ solution.

CEM I

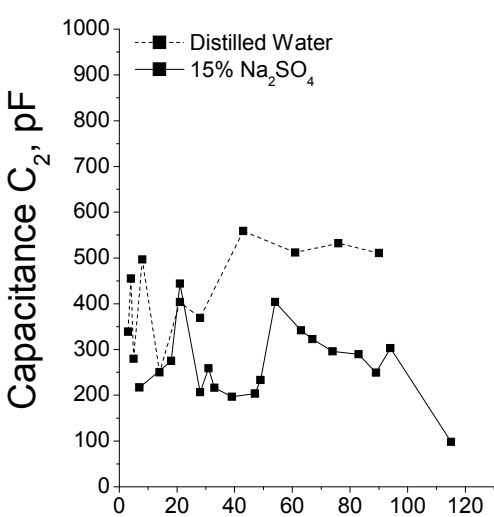

CEM III

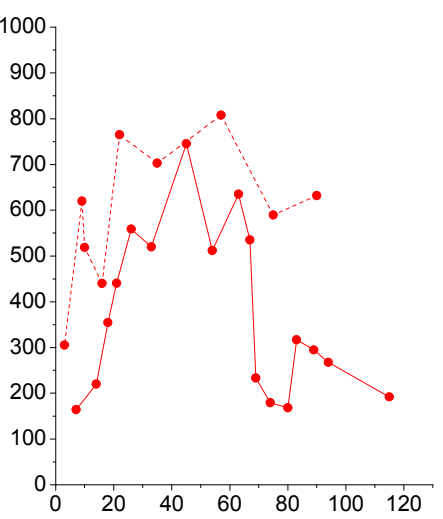

Hardening age, days
CEM IV

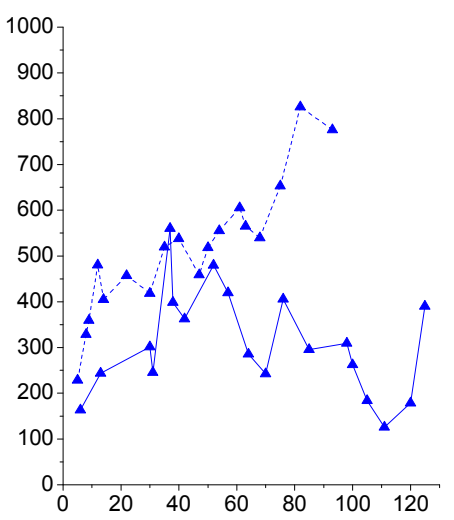

Figure 7. Comparison of capacitance $\mathrm{C}_{2}$ values obtained for CEM I, CEM III and CEM IV grouts kept in contact with distilled water (dotted line) and $15 \% \mathrm{Na}_{2} \mathrm{SO}_{4}$ solution (continuous line). 


\subsection{Electrical Resistivity}

The results of electrical resistivity obtained for grouts maintained in contact with sodium sulphate solution and distilled water are depicted in Figure 8. For both conditions, this parameter rose with time and it was higher for CEM IV grouts, followed by CEM III ones, and the lowest electrical resistivity values corresponded to CEM I samples. A slight decrease of this parameter has been observed for grouts which incorporated active additions exposed to sulphate solutions at later ages, although this fall was practically insignificant compared to higher decrease noted in impedance spectroscopy parameters. Finally, as happened with impedance resistances $R_{1}$ and $R_{2}$, the absolute values of electrical resistivity cannot be also compared between the both media studied, because they are influenced by their different conductivity.

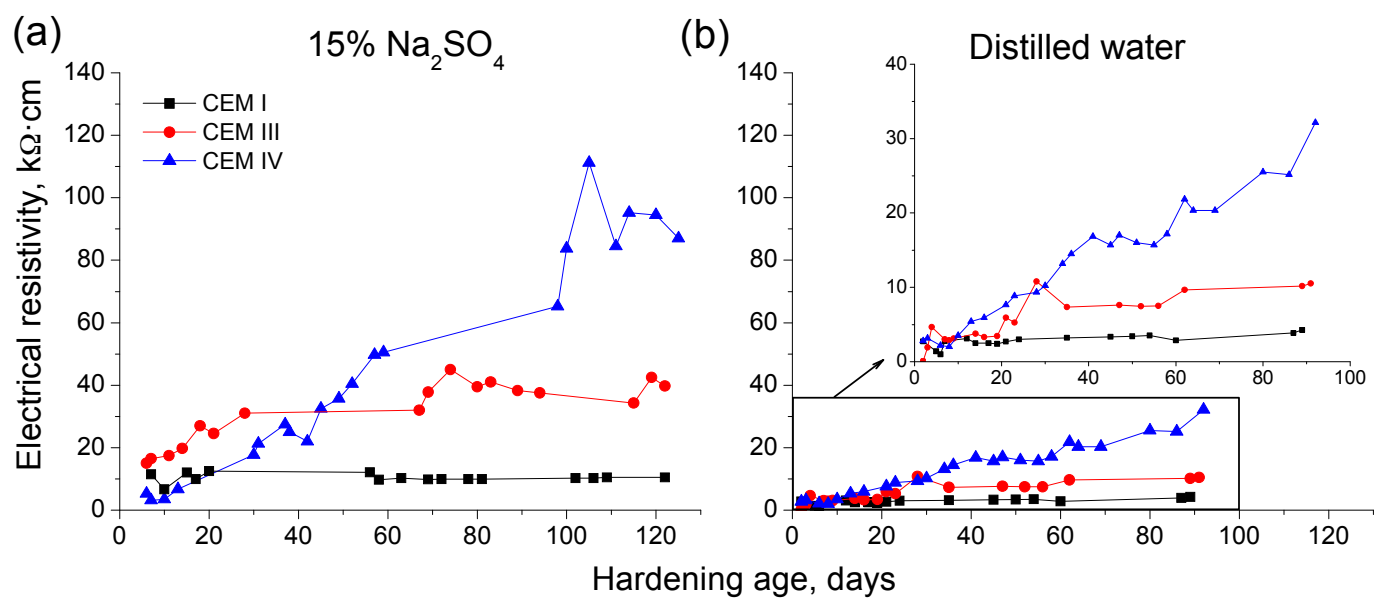

Figure 8. Changes with time of electrical resistivity for CEM I, III and IV grouts exposed to: $15 \% \mathrm{Na}_{2} \mathrm{SO}_{4}$ solution (a); and distilled water (b).

\subsection{Mercury Intrusion Porosimetry}

The total porosity results for grouts exposed to sodium sulphate solution are depicted in Figure 9. In general, this parameter showed a decreasing tendency between 28 and 120 days for all cements studied. However, it has been observed a little increase of CEM I grouts total porosity between 60 and 90 days of exposure, although it returned to reduce since then until 120 days. For CEM III and IV grouts, the slight increase of this parameter was produced later, between 90 and 120 days. The lowest values of total porosity corresponded to CEM I grouts at all ages and the highest to the CEM III ones, whereas the reduction with time of this parameter was higher for grouts with slag and fly ash cements.

The total porosity comparison between grouts exposed to sodium sulphate solution and those submerged in distilled water can be observed in Figure 10. For CEM I grouts, since 28 days, the porosity is lower for those hardened in distilled water, but at 90 days of exposure there was no difference between both media. The total porosity of CEM III samples was higher for those immersed in $15 \%$ $\mathrm{Na}_{2} \mathrm{SO}_{4}$ solution, however, in the case of CEM IV ones, this parameter was greater for distilled water medium during all the study time.

The evolution of pore size distributions for grouts exposed to sodium sulphate solution is shown in Figure 11. The pore size range between 10 and $100 \mathrm{~nm}$ is the majority one at all ages for the three cements studied. Furthermore, it has been observed a progressive pore refinement with time for all the grouts. The microstructure of slag and fly ash cement grouts was more refined than CEM I one, especially at early ages. For CEM III and IV grouts the main pore structure refinement was produced since 28 and 60 days, and for grouts prepared using CEM I, the major refinement has been observed between 90 and 120 days. If the pore size distributions of grouts with active additions are compared, the porous network of CEM IV grouts is a little more refined than for CEM III one, mainly at 120 days of 
exposure to the aggressive medium. Finally, it is important to note that CEM III grouts microstructure showed a slight loss of refinement between 90 and 120 days, as suggested the reduction of percentage of pores volume with a size less than $100 \mathrm{~nm}$. For the rest of grouts, no refinement decrease has been observed in the long-term.

Depending on the hardening medium, the development of grouts microstructure showed differences, as can be observed in Figure 12. For CEM I and CEM III samples, the refinement of porous network was greater for those immersed in distilled water, as stand out the relatively high percentage of pores with diameters less than $10 \mathrm{~nm}$. On the other hand, for CEM IV grouts at 28 and 90 days, respectively, the microstructure was more refined for those exposed to sodium sulphate solution, showing a larger percentage of pores smaller than $100 \mathrm{~nm}$.

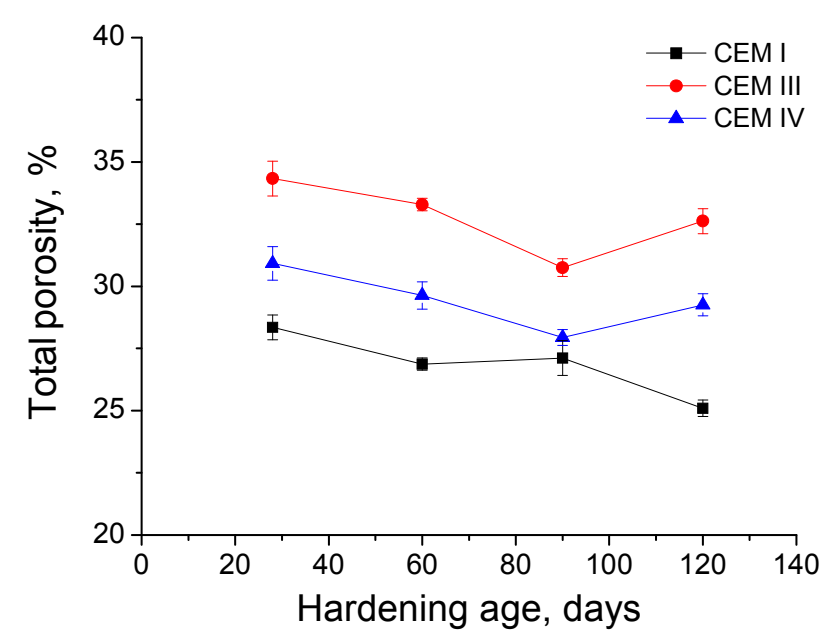

Figure 9. Total porosity results for CEM I, CEM III and CEM IV grouts immersed in a $15 \% \mathrm{Na}_{2} \mathrm{SO}_{4}$ solution until 120 days.

CEM I

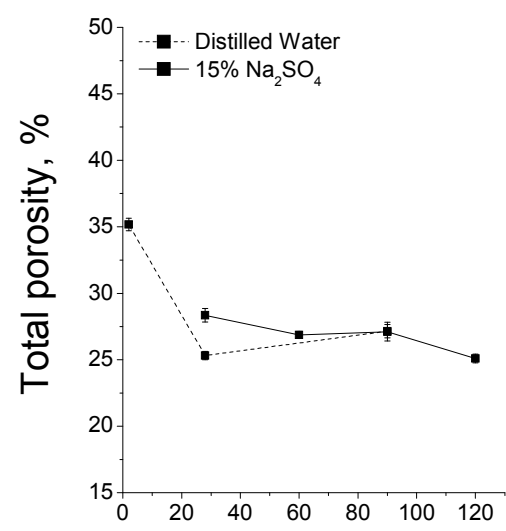

CEM III

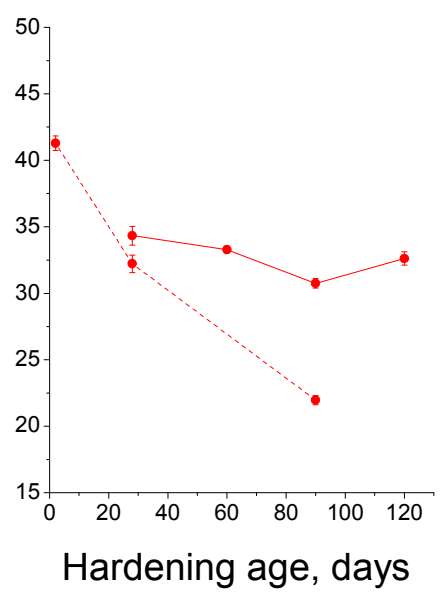

CEM IV

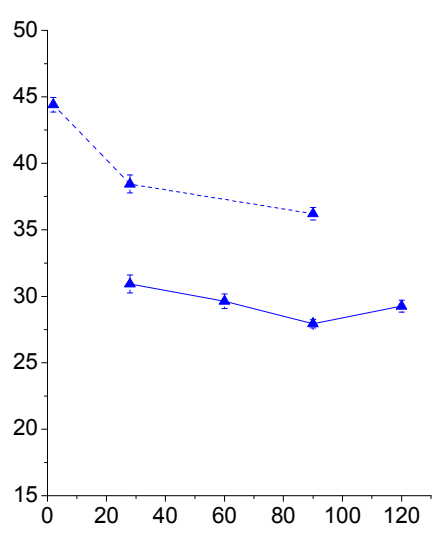

Figure 10. Comparison of total porosity results obtained for CEM I, CEM III and CEM IV grouts exposed to distilled water (dotted line) and $15 \% \mathrm{Na}_{2} \mathrm{SO}_{4}$ solution (continuous line). 


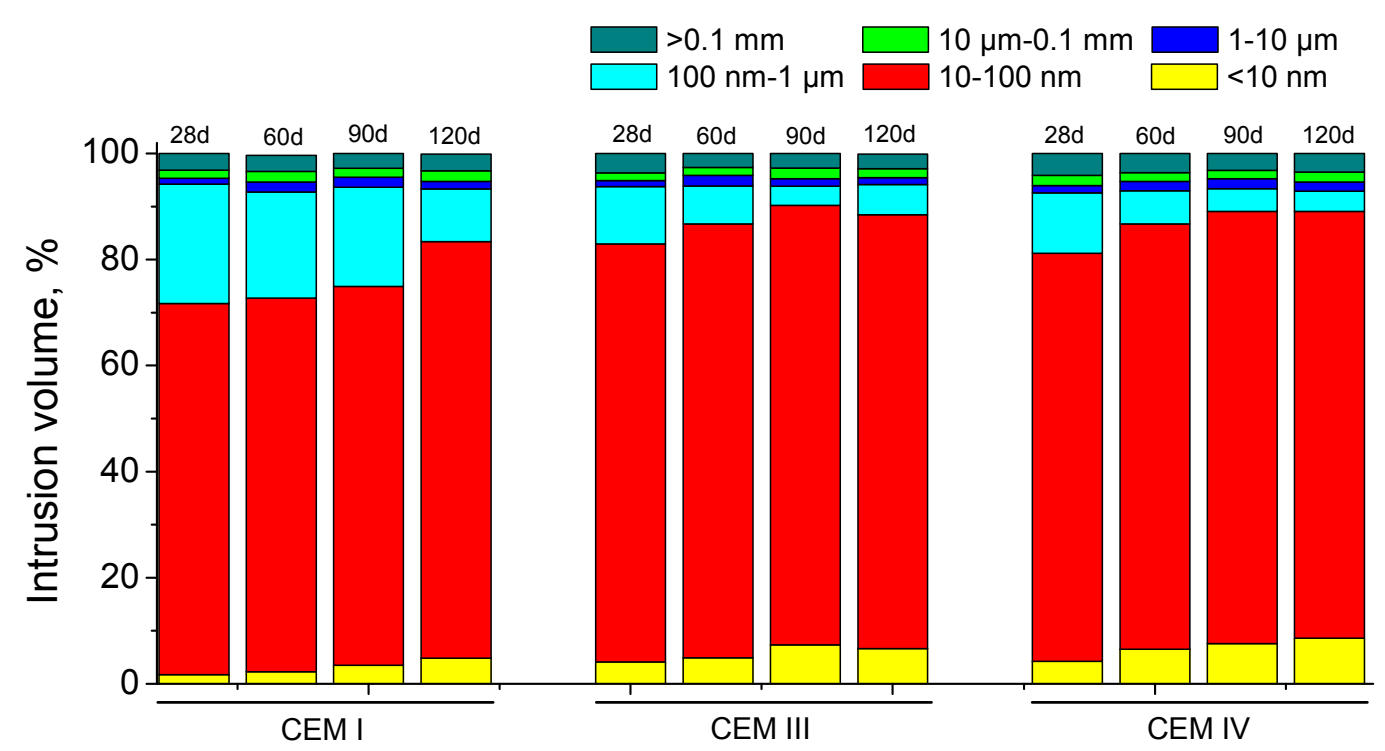

Figure 11. Pore size distributions (in percentage) for CEM I, III and IV grouts immersed in $15 \% \mathrm{Na}_{2} \mathrm{SO}_{4}$ solution.

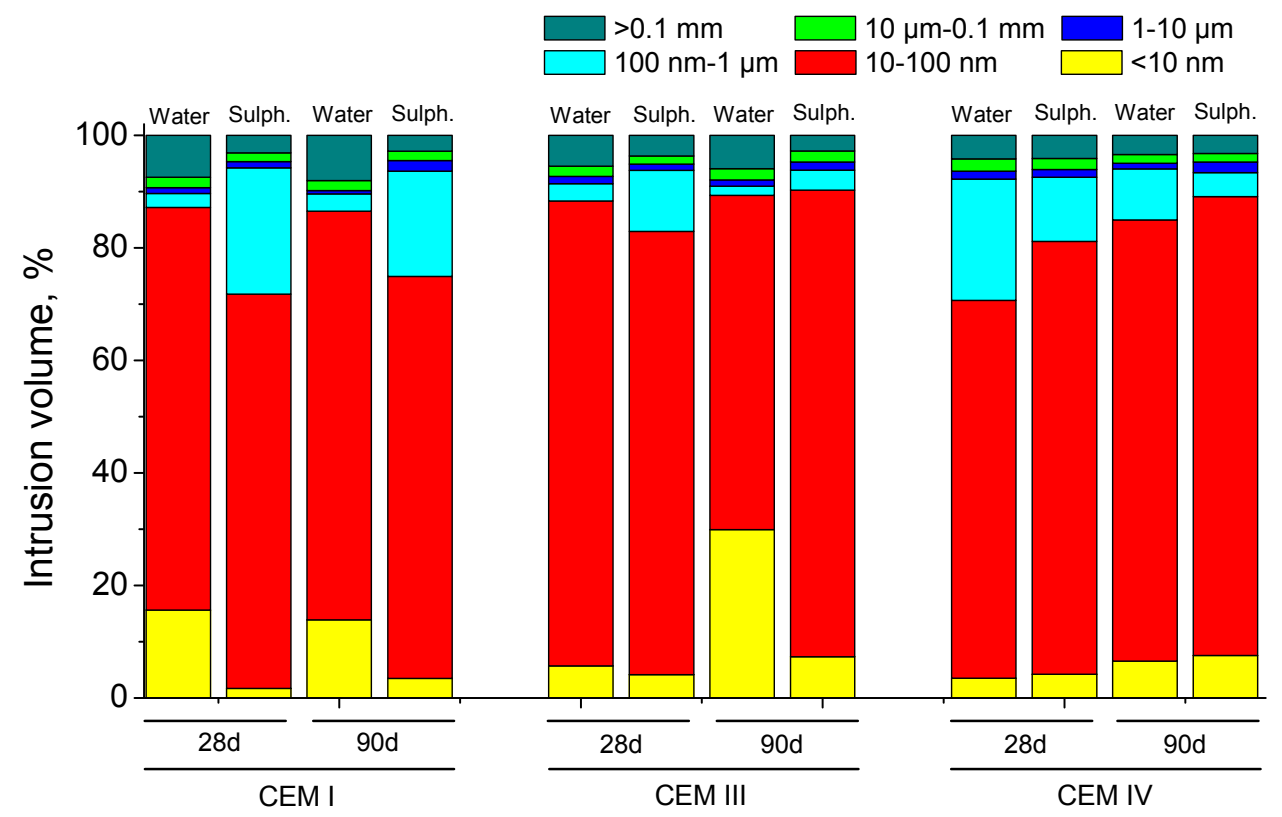

Figure 12. Comparison of pore sizes distributions of grouts at 28 and 90 days of immersion in distilled water and $15 \% \mathrm{Na}_{2} \mathrm{SO}_{4}$ solution respectively.

With respect to percentage of $\mathrm{Hg}$ retained in the samples at the end of the experiment for grouts exposed to $15 \% \mathrm{Na}_{2} \mathrm{SO}_{4}$ solution (see Figure 13), this parameter kept practically constant for CEM I samples. Nevertheless, for CEM III ones, Hg retained decreased with time, mainly from 90 to 120 days, when it showed the lowest value of this parameter of all studied cements. The $\mathrm{Hg}$ retained increased until 90 days for CEM IV grouts and fell between then and 120 days, although at that age, its value was the greatest of all analysed grouts.

If it is compared the results of $\mathrm{Hg}$ retained for $15 \% \mathrm{Na}_{2} \mathrm{SO}_{4}$ solution with those obtained for distilled water (see Figure 14), several differences can be noted, especially in the case of grouts with active additions. Firstly, for CEM III grouts $\mathrm{Hg}$ retained increased with age for samples submerged in distilled water, which is a great difference in comparison with the important fall observed for those 
exposed to sodium sulphate solution. On the other hand, CEM IV grouts hardened in contact with distilled showed lower values of $\mathrm{Hg}$ retained than $15 \% \mathrm{Na}_{2} \mathrm{SO}_{4}$ solution ones. Finally, for CEM I grouts there was not practically difference regarding this parameter between both exposure media studied.

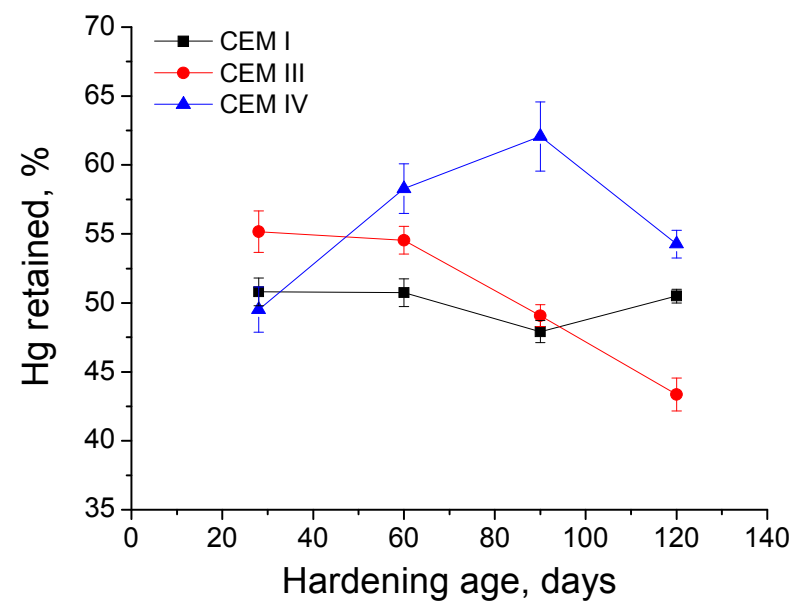

Figure 13. Percentage of $\mathrm{Hg}$ retained at the end of experiment for grouts exposed to sodium sulphate solution.

CEM I

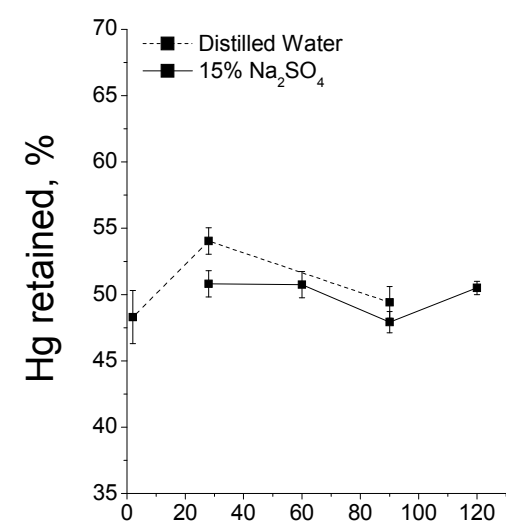

CEM III

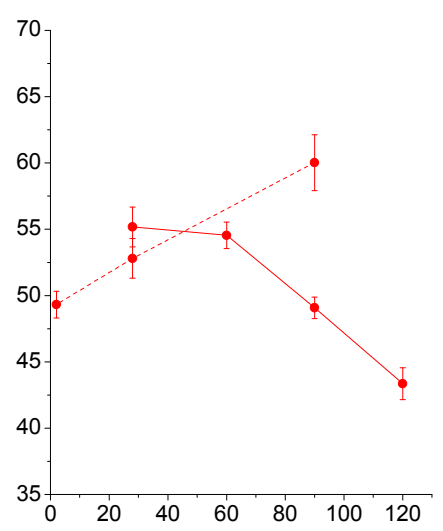

Hardening age, days
CEM IV

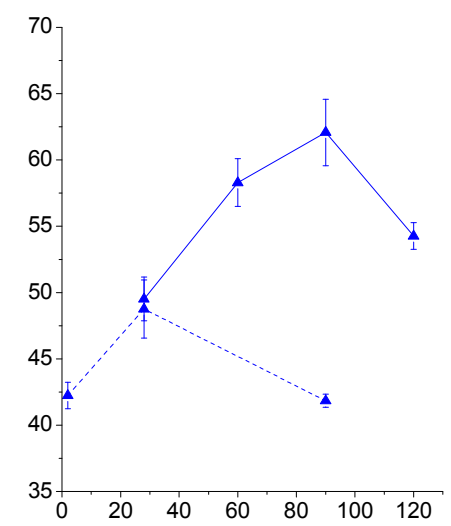

(20

Figure 14. Results of percentage of $\mathrm{Hg}$ retained in the samples at the end of experiment obtained for CEM I, CEM III and CEM IV grouts exposed to distilled water (dotted line) and $15 \% \mathrm{Na}_{2} \mathrm{SO}_{4}$ solution (continuous line).

\subsection{Compressive Strength}

The compressive strengths of the grouts at 28 days are compiled in Table 3 . The greatest values of this parameter have been observed for samples kept in distilled water, although the difference with those exposed to $15 \% \mathrm{Na}_{2} \mathrm{SO}_{4}$ solution was not excessive. In particular, the fall of compressive strength for samples submerged in sodium sulphate solution, compared to those hardened in water, was about $15 \%$ for CEM I grouts, $10 \%$ for CEM III ones and $4 \%$ for CEM IV ones. Moreover, the highest compressive strength corresponded to CEM I grouts and the lowest were registered for CEM IV ones. 
Table 3. The 28-day compressive strength for studied cement grouts (standard deviation in brackets).

\begin{tabular}{ccc}
\hline \multirow{2}{*}{ Cement Type } & \multicolumn{2}{c}{ Exposure Medium } \\
\cline { 2 - 3 } & Distilled Water & ${\mathbf{1 5 \% ~} \mathbf{~ a a}_{\mathbf{2}} \mathbf{S O}_{\mathbf{4}}}$ \\
\hline CEM I & $49.7 \mathrm{MPa}(1.56)$ & $43 \mathrm{MPa}(2.65)$ \\
CEM III & $42.7 \mathrm{MPa}(2.23)$ & $38.7 \mathrm{MPa}(2.08)$ \\
CEM IV & $31.1 \mathrm{MPa}(1.88)$ & $30.1 \mathrm{MPa}(1.39)$ \\
\hline
\end{tabular}

\section{Discussion}

In relation to microstructure characterization using impedance spectroscopy, both resistances $\mathrm{R}_{1}$ and $R_{2}$ are related to the electrolyte which fills the pores of the sample [60]. Particularly, the resistance $R_{1}$ is associated with the percolating pores of the sample [60] and the resistance $R_{2}$ is related to all the pores of the sample [60]. Therefore, it may be expected that these parameters would increase when the microstructure of the sample becomes more refined and its total porosity decreases, as a consequence of the development of hydration and pozzolanic reactions. As products of these reactions, new solid phases would be formed, which would entail a reduction of pore sizes of the samples.

The increasing tendency of resistances $R_{1}$ (see Figure 2) and $R_{2}$ (see Figure 3 ) in the short-term for the grouts exposed to sodium sulphate solution could be due to the abovementioned progressive microstructure refinement produced by the new solids formation, as consequence of the clinker and slag hydration, and the pozzolanic reactions of fly ash. The subsequent rise of both resistances for CEM IV grouts hardened in this medium, could be explained because the pozzolanic reactions of fly ash start to develop later than slag and clinker hydration [10,11], so more time is needed to observe their effects in the porous network of fly ash grouts.

The decrease of impedance resistances $R_{1}$ and $R_{2}$ of the grouts in the long-term (see Figures 2 and 3) could indicate an increase of porosity of the samples, due the formation of expansive products as a consequence of sulphate attack. As has been previously mentioned, the resistance $R_{1}$ is associated with percolating pores of the sample, so the aggressive ions can access directly into them, which could produce a faster and higher degree of sulphate attack. On the other hand, the resistance $R_{2}$ includes all pores of the samples, so in addition to the accessible ones, this parameter takes into account the occluded pores, which do not received directly the sulphate attack. Then, the microstructure refinement caused by the development of hydration and pozzolanic reactions would continued in this occluded pores, entailing higher values of resistances $R_{2}$, which would balance out the decrease of this parameter due to the destruction of microstructure produced by sulphate attack in the percolating pores. However, the lower resistance values (related to higher size pores) will be those that controlled the final resistance $R_{2}$ results, and this could explain the fall of this parameter also noted in the long-term, although it was not as high as has been observed for resistance $R_{1}$.

The resistances $R_{1}$ and $R_{2}$ showed different behaviour for grouts immersed in sodium sulphate solution than for those hardened in distilled water (see Figures 2 and 3). At early ages, both resistances grew with time for grouts in contact with water, which could mean a progressive pore network refinement produced by the new solids formation as products of hydration and pozzolanic reactions. Nevertheless, it has not been observed a decrease at later ages of both impedance resistances for grouts submerged in distilled water, as happened for those exposed to sulphate attack. This result would corroborate the hypothesis that in the long-term expansive products was formed in the grouts immersed in sulphate solution, raising their porosity and reducing their microstructure refinement.

The next impedance spectroscopy results to discuss are those obtained for capacitance $C_{1}$. This parameter is related to the solid fraction in the samples [60], so it is expected that this parameter increases as solid formation is produced due to the development of slag and clinker hydration and fly ash pozzolanic reactions. Besides, it could be also supposed that the capacitance $C_{1}$ decreases when there is a loss of solid fraction of the samples caused by the destruction of their microstructure due to the sulphate attack. 
With respect to capacitance $C_{1}$ results for grouts in contact with sodium sulphate solution (see Figure 4), the initial increase and following decrease observed for this parameter coincides with resistance $R_{1}$ and $R_{2}$ results. As has been previously explained, they could be due to the early solids formation, as a consequence of hydration and pozzolanic reactions, and the later appearance of expansive products produced during the sulphate attack. Furthermore, the different age when it was reached the maximum $C_{1}$ for each cement type, especially for CEM IV grouts, was also in accordance with $R_{1}$ and $R_{2}$ results, and reveals the delaying between the beginning of fly ash pozzolanic reactions and clinker and slag hydration $[10,11]$. The fact that there was not a great difference between the capacitance $C_{1}$ values obtained for the different grouts and exposure conditions studied (Figures 4 and 5), could indicate that the solid phase of the samples was very similar for the three cement types, independently of the different pore size distribution for each one.

Regarding the comparison between the capacitance $C_{1}$ results for both media studied (see Figure 5), the higher values showed by CEM I grouts exposed to sulphate solution compared to distilled water ones, could be related to the silting of the pores due to the formation of ettringite. This could also explain the similar result observed for CEM III and IV grouts. In addition, the fall at later ages of capacitance $C_{1}$, which was not observed for grouts hardened in distilled water, could indicate the appearance of microcracking, because the pore structure was no longer able to contain the expansive products formed during the sulphate attack.

The low frequency capacitance $C_{2}$ has been associated with the pore surface in contact with electrolyte present in the material and it is related to the formation of CSH gel layers, which occupy the pores [65]. The hydration and pozzolanic reactions products are deposited on the pore surface and they increase the specific surface of the pores [45], because these products form rough structures. Moreover, it could be expected that those rough structures would progressively destroyed when the sulphate attack is advanced enough, which would imply a reduction of the capacitance $C_{2}$.

For samples exposed to sodium sulphate solution (see Figure 6), the capacitance $C_{2}$ showed a similar tendency than that observed for the rest of impedance spectroscopy parameters, previously described and discussed. The highest maximum values of this parameter have been noticed for grouts with slag and fly ash. This result would indicate that this samples would have a greater specific pore surface compared to CEM I ones, which would imply a more refined microstructure, corroborating the resistances $R_{1}$ and $R_{2}$ results. The decrease of capacitance $C_{2}$ showed by the grouts since a certain age (see Figure 6) would mean a loss of specific pore surface and tortuosity of the porous network, which could be produced by the appearance of expansive products as a consequence of sulphate attack. These products would break the structures formed on the pore surface during the hydration and pozzolanic reactions.

In general, the capacitance $\mathrm{C}_{2}$ was higher for grouts hardened in distilled water than for those exposed to sodium sulphate solution (see Figure 7), although for each cement type in the short-term this parameter was very similar for both conditions. The optimum hardening condition, as it is the immersion in water distilled, facilitates the development of hydration and pozzolanic reactions, so the specific pore surface increases and the microstructure becomes more refined, as showed the greater values of capacitance $C_{2}$ for grouts exposed to this condition. Besides, no loss of refinement is produced in the long-term, as indicated the fact that this capacitance kept practically constant. The similar behaviour of capacitance $C_{2}$ in the short-term observed for grouts exposed to sodium sulphate solution could be due to a combined action of solid formation by the hydration and pozzolanic reactions and an initial silting of the pores produced by the formation of ettringite, which would increased the solid-electrolyte interphase and consequently rising the $\mathrm{C}_{2}$ values. In subsequent stages of the sulphate attack, the continuous ettringite formation would damage the rough structures formed on the pore surface, especially for smaller pores, causing a drop of capacitance $\mathrm{C}_{2}$.

The electrical resistivity results for samples exposed to sulphate solution were very similar than impedance resistance $R_{2}$ ones (see Figure 8). Nevertheless, it is important to emphasize that the tendency change in the long-term evolution of resistivity is not as clear as has been observed for 
impedance resistance $R_{2}$. This could be due to the different geometry of samples used for each technique, and in particular related to their different relationship between surface and volume. For impedance spectroscopy, $10 \mathrm{~cm}$-diameter disks with $2 \mathrm{~cm}$ of thickness were exposed to sulphate medium, and for electrical resistivity, cylinders of $30 \mathrm{~cm}$ height and $7.5 \mathrm{~cm}$ diameter were tested. Therefore, the relationship surface/volume was approximately twice for impedance spectroscopy specimens than for resistivity ones. Then, if the relationship surface/volume is higher, it could be expected that the sulphate attack effects were visible at earlier ages, which would justify the fact that these effects have been detected before by impedance spectroscopy than by the monitoring of electrical resistivity, as has been observed in this research.

On the other hand, another explanation of this different behaviour of electrical resistivity, in which hardly decrease was observed at greater ages, could be the fact that this parameter has been measured using a superficial technique, as is Wenner four-point test. As a consequence, maybe it has been only registered the precipitation of sulphates in the most superficial pores of the samples, which would increase considerably the resistivity. This contrasted with impedance spectroscopy, which is a global technique and allows measurements through the specimens, not only on their surface, obtaining in this way more reliable information of pore network of the grouts. Finally, regarding the comparison between electrical resistivity results obtained for each storage condition studied (see Figure 8), the grouts immersed in distilled water showed a continuous rising tendency of this parameter, especially for CEM IV samples, while those exposed to sulphate solution tended to stabilize or even decrease in the long-term. The behaviour of grouts in distilled water medium would indicate the effects of progressive development of hydration and pozzolanic reactions, in accordance with previously discussed results. For grouts hardened in contact with sodium sulphate solution, the different behaviour of resistivity at greater ages would be related to the effects of sulphate attack in the microstructure, despite the already explained limitations of Wenner four-point test.

In relation to classical mercury intrusion porosimetry, the total porosity of grouts exposed to sodium solution decreased in the short-term (see Figure 9), which would indicate a solid formation and a reduction of total volume of pores. This result is in agreement with impedance spectroscopy and resistivity ones, and it could be a consequence of the new products formation through the development of slag and clinker hydration and fly ash pozzolanic reactions $[5,13]$. On the other hand, the small rise of total porosity observed for CEM III and IV grouts could be related to the sulphate attack effects, which would involve the formation of expansive products $[19,20,22,72]$, producing a loss of solid fraction in the sample. These results were in line with those obtained for other authors [56,73]. Moreover, there was not a high difference between the total porosities obtained for the three types of grouts studied. This result is in keeping with the impedance capacitance $C_{1}$ ones (see Figure 4), previously discussed, and therefore, they would indicate that the solid fraction was similar for all grouts, regardless of cement type used. The similar behaviour of total porosity and capacitance $C_{1}$ would be justified because both parameters give information about the total proportion of solids in the material, without considering its pore size distribution [45].

The total porosity of grouts showed different results for each storage condition and cement type (see Figure 10). The total porosity of CEM I grouts was very similar for both media studied, and this could be related to the development of clinker hydration, especially for those exposed to an optimal condition, as immersion in distilled water. For CEM I grouts in contact with aggressive sulphate solution, the combined effect of clinker hydration and the pores silting caused by the precipitation of sulphates and other salts, as consequence of $\mathrm{C}_{3} \mathrm{~A}$ reactions, could play an important role in their total porosity results. The beneficial effect of optimum hardening condition was more prominent for CEM III samples, and the immersion in distilled water would favour the development of slag hydration and new solids formation $[45,74]$, as suggested the great fall of their total porosity with age, compared to those submerged in sulphate solution, in which the formation of expansive products would hinder a more considerable decrease of porosity. Finally, in relation to CEM IV grouts, the lowest total porosity corresponded to those hardened in contact with sulphate solution. This result could be due to the 
possible effect of $\mathrm{Na}_{2} \mathrm{SO}_{4}$ as an activator of pozzolanic reactions of fly ash, and it is agreement with other authors $[75,76]$.

The pore size distributions of the grouts exposed to sulphate solution (see Figure 11) showed a progressive microstructure refinement with age, regardless of cement type used. These results are in keeping with those obtained in the short-time for impedance spectroscopy $R_{1}$ and $R_{2}$ resistances and electrical resistivity. They would point out the solid phases formation, mainly by the development of slag and clinker hydration and pozzolanic reactions of fly ash $[5,11]$, so the pore size distribution is shifted towards finer pores. Furthermore, the microstructure was more refined for grouts with active additions than for CEM I ones, which is also in accordance with impedance spectroscopy and electrical resistivity results, and with other researches too [5,33,77], even for the exposure to sulphate attack [56]. At 28 days, the pore network of CEM III grouts was a little more refined than for CEM IV ones. This fact would be a result of the different behaviour of slag and fly ash. The hydraulic nature of slag allows that they start to react since the mixing of the grouts [5], while the pozzolanic nature of fly ash entails that its reactions start later than the beginning of clinker hydration [78], because they need the presence of portlandite formed in this hydration $[10,11]$. Then, a delay in microstructure refinement process is produced, as it was observed in the pore size distribution results, which is also agreement with the later increase of impedance parameters and electrical resistivity for CEM IV grouts, previously explained.

Nevertheless, no noticeable loss of pore network refinement has been noted in the long-term for grouts immersed in sulphate solution (see Figure 11), in contrast to impedance spectroscopy results. This result could be related to the drawbacks of mercury intrusion porosimetry $[69,70]$ and it would suggest that more time would be needed for detecting the possible effects of sulphate attack in the pore size distribution of grouts using this technique. However, mercury intrusion porosimetry also allows studying the pore size distribution of the samples using the curves logarithm of differential intrusion volume versus pore size, in which the peaks reveal the presence of pores families. Then, in order to detect those possible effects of sulphate attack in pore size distribution of the grouts, these curves were also plotted (see Figures 15 and 16).

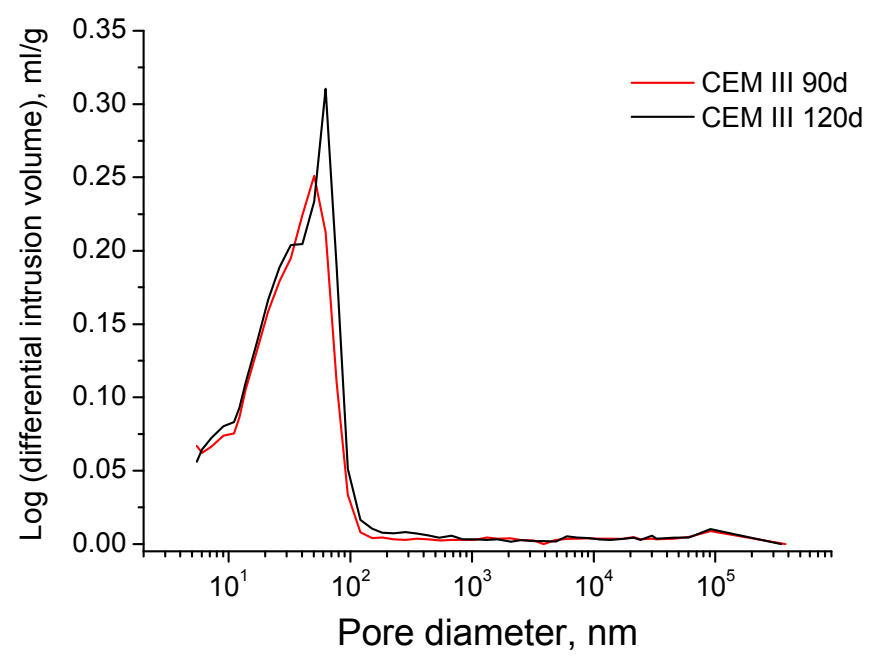

Figure 15. Curves of the logarithm of differential intrusion volume versus pore size obtained at 90 and 120 hardening days for CEM III grouts exposed to sodium sulphate solution.

For CEM III grouts, the main family of pores at 90 and 120 days, which is indicated by the highest peak of curves depicted in Figure 15, belonged to the pore range comprised between 10 and $100 \mathrm{~nm}$. However, this family showed a higher pore size at 120 days, because the peak is closer to $100 \mathrm{~nm}$ at that age than at 90 days. Therefore, it is confirmed that a slight loss of pore network refinement was produced, which was not detected in the representation of pore size distribution using fixed pore 
ranges (see Figure 11). The curves logarithm of differential intrusion volume versus pore size for CEM IV grouts (see Figure 16) showed that the loss of microstructure refinement was not as clear as that noted for CEM III ones. As can be observed in Figure 16, for CEM IV samples only one family of pores existed in the range from 10 to $100 \mathrm{~nm}$ at 90 days, which was wider than that observed for CEM III ones. This only family developed in two different families at 120 days, as indicated the fact that the peak observed at 90 days was divided in two ones at 120 days. This could be due to the combined effect of the sulphate attack, which would start to reduce the microstructure refinement, and the new solids formation as a products of fly ash pozzolanic reactions, which would be still developing because they are delayed in comparison to clinker hydration [10,11]. On the one hand, the effects of expansive products produced by sulphate attack would move the original 90 days peak towards higher pore sizes, giving room to the right peak observed at 120 days in Figure 16. On the other hand, the products of the delayed pozzolanic reactions of fly ash would tend to move the 90 days peak towards smaller pore sizes, leading to the left peak at 120 days in Figure 16. This could explain the evolution of the curve logarithm of differential intrusion volume versus pore size observed for CEM IV grouts, and the appearance of two peaks observed at 120 days.

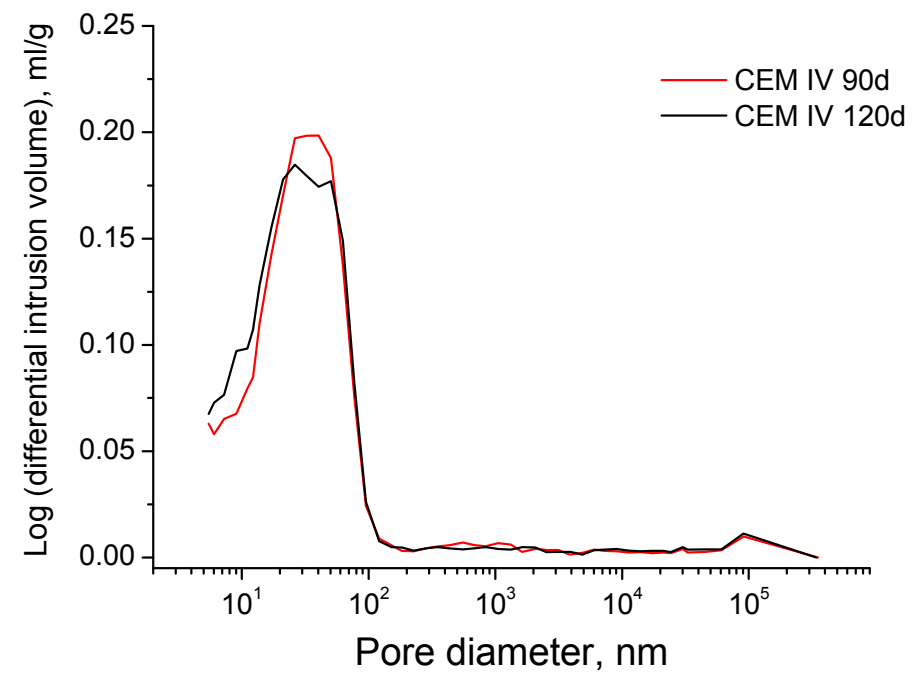

Figure 16. Curves of the logarithm of differential intrusion volume versus pore size obtained at 90 and 120 hardening days for CEM IV grouts immersed in sodium sulphate solution.

Regarding the comparison between the pore size distributions of the grouts exposed to both media studied (see Figure 12), for CEM I and III grouts the microstructure refinement was higher for those hardened in contact with distilled water. This result could be related to the formation of expansive products during the sulphate attack, which would produce cracks in the pore network, reducing the percentage of smaller pores. On the other hand, for CEM IV grouts, the microstructure was more refined for those immersed in sodium sulphate solution than for those stored in distilled water. This result is in line with total porosity ones, and it could be due to the effect of pozzolanic activation of fly ash produced by the sodium sulphate $[75,76]$.

The $\mathrm{Hg}$ retained in the sample at the end of the MIP test gives information about the tortuosity of the pore network [60]. In general, the results of this parameter obtained for the grouts exposed to sulphate attack (see Figure 13) are in keeping with the rest of MIP results previously discussed. The highest values of $\mathrm{Hg}$ retained observed for grouts with active additions would mean a greater tortuosity of the microstructure, which coincides with their higher pore refinement and with their greater specific pores surface, suggested by impedance spectroscopy capacitance $C_{2}$ results. The fall at later ages of $\mathrm{Hg}$ retained (observed first for CEM III grouts and later for CEM IV ones) is also in accordance with the majority of results of this research, and it could be associated to the damage 
produced by sulphate expansive products in the pore structure of the samples, which would reduce its tortuosity. Moreover, it is important to emphasize that for CEM III grouts practically coincided the age (between 50 and 60 days approximately) when $\mathrm{Hg}$ retained and impedance spectroscopy capacitance $\mathrm{C}_{2}$ started to fall. Lastly, comparing the $\mathrm{Hg}$ retained results for both storage conditions studied, it is interesting to note that the highest values of this parameter for CEM IV samples were obtained for those immersed in sulphate solution. This result would confirm again the important effect of $\mathrm{Na}_{2} \mathrm{SO}_{4}$ as an activator of pozzolanic reactions of fly ash [75,76].

Overall, the results of microstructure characterization carried out using impedance spectroscopy, mercury intrusion porosimetry and electrical resistivity are in agreement. They showed a first stage of microstructure refinement as a consequence of the development of clinker and slag hydration and fly ash pozzolanic reactions. Furthermore, the ettringite formation due to sulphate attack could initially contribute to this pore network refinement, until the pores were filled enough. After that, it would start a second stage, in which the damages in the microstructure produced by expansive products become more important, and it could be supposed that they would be the major process which would control the evolution of the microstructure, although the hydration and pozzolanic reactions could be still producing. During this second phase, a loss of microstructure refinement is produced, showed mainly by the decrease of impedance spectroscopy parameters. The abovementioned mechanism is in keeping with that proposed by other authors [79].

Finally, the compressive strength results at 28 days (see Table 3 ) are influenced by the different strength type of cement used, although the grouts which incorporate active additions showed a smaller loss of strength in sodium sulphate media than CEM I ones, compared to distilled water medium. Then, the highest values of this parameter have been observed for CEM I grouts as it was expected, because it was used a high early strength cement type. Although the strength type of slag cement was the same than for CEM I, the compressive strength of CEM III grouts was lower, which was also expected because the slag cement was low early strength type. At last, the smallest compressive strength was observed for CEM IV grouts, due to the lowest strength type of this cement.

\section{Conclusions}

The main conclusions that can be drawn from the results previously discussed can be summarized as follows:

- In general, slag and fly ash cement grouts for micropiles showed a more refined microstructure than CEM I ones for both sodium sulphate solution and distilled water hardening media.

- In the short-term (until approximately 40 hardening days), the microstructure of the grouts exposed to sodium sulphate solution becomes more refined, due to the formation of solid phases as products of clinker and slag hydration and fly ash pozzolanic reactions. Moreover, the ettringite formation as a consequence of sulphate attack would also contribute to this microstructure refinement.

- In the long-term (approximately from 60-90 days, depending on the cement type, up to 120 days of exposure), for grouts in contact with sodium sulphate solution, when enough silting of pores by expansive products formation has been produced, the continuous sulphate attack would damage the rough structures formed in the pore surface, causing a loss of microstructure refinement, independently that the hydration and pozzolanic reactions could be still producing.

- The exposure of grouts to an optimum hardening condition, like the immersion in distilled water, favours the development of hydration and pozzolanic reactions and improves the development of their microstructure, reducing the porosity and increasing the refinement of the pore network.

- The development of microstructure for CEM IV grouts was delayed in comparison with CEM I and III ones. This could be associated with the later beginning of fly ash pozzolanic reactions with respect to clinker and slag hydration. 
- The compressive strength of the grouts at 28 days was influenced by the different strength type of cement used. However, the loss of compressive strength for samples submerged in sodium sulphate solution, compared to those hardened in distilled water, was lower for slag and fly ash cement grouts than for CEM I ones.

- Fly ash grouts exposed to sodium sulphate solution showed a better behaviour in relation to microstructure development, compared to those submerged in distilled water. This could be due to the possible effect of $15 \% \mathrm{Na}_{2} \mathrm{SO}_{4}$ as an activator of pozzolanic reactions of fly ash.

- In general, the microstructure characterization carried out using impedance spectroscopy, mercury intrusion porosimetry and electrical resistivity are in agreement. However, it seems that non-destructive impedance spectroscopy is the most sensitive technique for following the changes in the porous network of slag and fly ash cement grouts for micropiles exposed to an aggressive sodium sulphate medium.

- In view of the results obtained in this research, the micropiles made using fly ash and slag cement grouts could have a good performance in contact with aggressive sodium sulphate media, even better than ordinary Portland cement ones.

Acknowledgments: The fee for publishing this open access paper has been provided by the R\&D Center of Excellence in Architecture, Engineering and Design of European University (Spain). The research work included in the paper has been financially supported by the University of Alicante (Spain) through project GRE13-25 and the "Ministerio de Economía y Competitividad" (formerly "Ministerio de Ciencia e Innovación") of Spain and FEDER through project BIA2011-25721. The authors also wish to thank Cementos Portland Valderrivas S.A. for providing the cements used in this study.

Author Contributions: This paper includes a part of the results obtained in the master's final project carried out by J.M.O.Á., under the supervision of M.D.E.P. and R.R.R.E., to obtain the Civil Engineering Master's degree at European University (Spain). J.M.O.Á. wrote the paper. J.M.O.Á. and J.L.P.N. performed the experiments. M.D.E.P., R.R.R.E. and I.S.M. supervised the research work and revised the paper. All authors contributed to conceive and design the experiments, and to analyse and discuss the results.

Conflicts of Interest: The authors declare no conflict of interest.

\section{References}

1. Armour, T.; Groneck, P.; Keeley, J.; Sharma, S. Micropile Design and Construction Guidelines-Implementation Manual Report FHWA-SA-97-070; Federal Highway Administration-US Department of Transportation: Washington, DC, USA, 2000; p. 376.

2. De Carreteras, D.G.; de Fomento, M.; Madrid, S. Guía para el Proyecto y la Ejecución de Micropilotes en Obras de Carretera; Ministerio de Fomento: Paseo de la Castellana, Spain, 2005.

3. AENOR. UNE-EN 14199: Ejecución de Trabajos Geotécnicos Especiales: Micropilotes; AENOR: Madrid, Spain, 2006; p. 54.

4. AENOR. UNE-EN 197-1:2011. Composición, Especificaciones y Criterios de Conformidad de los Cementos Comunes; AENOR: Madrid, Spain, 2011; p. 30.

5. Bijen, J. Benefits of slag and fly ash. Constr. Build. Mater. 1996, 10, 309-314. [CrossRef]

6. Demirboğa, R. Thermal conductivity and compressive strength of concrete incorporation with mineral admixtures. Build. Environ. 2007, 42, 2467-2471. [CrossRef]

7. Ganjian, E.; Pouya, H.S. The effect of Persian Gulf tidal zone exposure on durability of mixes containing silica fume and blast furnace slag. Constr. Build. Mater. 2009, 23, 644-652. [CrossRef]

8. Ortega, J.M.; Sánchez, I.; Climent, M.A. Influencia de diferentes condiciones de curado en la estructura porosa y en las propiedades a edades tempranas de morteros que contienen ceniza volante y escoria de alto horno. Mater. Constr. 2012, 63, 219-234.

9. Ponikiewski, T.; Gołaszewski, J. The effect of high-calcium fly ash on selected properties of self-compacting concrete. Arch. Civ. Mech. Eng. 2014, 14, 455-465. [CrossRef]

10. Papadakis, V.G. Effect of fly ash on Portland cement systems. Cem. Concr. Res. 1999, 29, 1727-1736. [CrossRef]

11. Wang, A.; Zhang, C.; Sun, W. Fly ash effects. Cem. Concr. Res. 2004, 34, 2057-2060. [CrossRef] 
12. Glinicki, M.; Jóźwiak-Niedźwiedzka, D.; Gibas, K.; Dąbrowski, M. Influence of blended cements with calcareous fly ash on chloride ion migration and carbonation resistance of concrete for durable structures. Materials 2016, 9, 18. [CrossRef]

13. Wedding, P.; Manmohan, D.; Mehta, P. Influence of pozzolanic, slag, and chemical admixtures on pore size distribution and permeability of hardened cement pastes. Cem. Concr. Aggreg. 1981, 3, 63-67. [CrossRef]

14. Bouikni, A.; Swamy, R.N.; Bali, A. Durability properties of concrete containing $50 \%$ and $65 \%$ slag. Constr. Build. Mater. 2009, 23, 2836-2845. [CrossRef]

15. Ortega, J.M.; Sánchez, I.; Climent, M.A. Durability related transport properties of OPC and slag cement mortars hardened under different environmental conditions. Constr. Build. Mater. 2012, 27, 176-183. [CrossRef]

16. Thomas, M.D.; Matthews, J. Performance of pfa concrete in a marine environment-10-year results. Cem. Concr. Compos. 2004, 26, 5-20. [CrossRef]

17. Thomas, M.D.A.; Scott, A.; Bremner, T.; Bilodeau, A.; Day, D. Performance of slag concrete in marine environment. ACI Mater. J. 2008, 105, 628-634.

18. Chalee, W.; Ausapanit, P.; Jaturapitakkul, C. Utilization of fly ash concrete in marine environment for long term design life analysis. Mater. Des. 2010, 31, 1242-1249. [CrossRef]

19. Bonakdar, A.; Mobasher, B. Multi-parameter study of external sulfate attack in blended cement materials. Constr. Build. Mater. 2010, 24, 61-70. [CrossRef]

20. Tixier, R.; Mobasher, B. Modeling of damage in cement-based materials subjected to external sulfate attack. I: Formulation. J. Mater. Civ. Eng. 2003, 15, 305-313. [CrossRef]

21. Santhanam, M.; Cohen, M.D.; Olek, J. Mechanism of sulfate attack: A fresh look. Part 1: Summary of experimental results. Cem. Concr. Res. 2002, 32, 915-921. [CrossRef]

22. Neville, A. The confused world of sulfate attack on concrete. Cem. Concr. Res. 2004, 34, 1275-1296. [CrossRef]

23. Kalousek, G.L.; Porter, L.C.; Benton, E.J. Concrete for long-time service in sulfate environment. Cem. Concr. Res. 1972, 2, 79-89. [CrossRef]

24. Monteiro, P.J.M.; Kurtis, K.E. Time to failure for concrete exposed to severe sulfate attack. Cem. Concr. Res. 2003, 33, 987-993. [CrossRef]

25. Ramyar, K.; İnan, G. Sodium sulfate attack on plain and blended cements. Build. Environ. 2007, 42, 1368-1372. [CrossRef]

26. Bentz, D.P.; Garboczi, E.J. Simulation studies of the effects of mineral admixtures on the cement paste-aggregate interfacial zone. ACI Mater. J. 1991, 88, 518-529.

27. Baghabra Al-Amoudi, O.S. Attack on plain and blended cements exposed to aggressive sulfate environments. Cem. Concr. Compos. 2002, 24, 305-316. [CrossRef]

28. Cao, H.T.; Bucea, L.; Ray, A.; Yozghatlian, S. The effect of cement composition and pH of environment on sulfate resistance of Portland cements and blended cements. Cem. Concr. Compos. 1997, 19, 161-171. [CrossRef]

29. Tian, B.; Cohen, M.D. Does gypsum formation during sulfate attack on concrete lead to expansion? Cem. Concr. Res. 2000, 30, 117-123. [CrossRef]

30. Živica, V. Sulfate resistance of the cement materials based on the modified silica fume. Constr. Build. Mater. 2000, 14, 17-23. [CrossRef]

31. Irassar, E.F.; Di Maio, A.; Batic, O.R. Sulfate attack on concrete with mineral admixtures. Cem. Concr. Res. 1996, 26, 113-123. [CrossRef]

32. Mehta, P.K. Effect of fly ash composition on sulfate resistance of cement. J. Am. Concr. Inst. 1986, 83, 994-1000.

33. Geiseler, J.; Kollo, H.; Lang, E. Influence of blast furnace cements on durability of concrete structures. ACI Mater. J. 1995, 92, 252-257.

34. Popovics, J.S.; Subramaniam, K.V.L. Review of ultrasonic wave reflection applied to early-age concrete and cementitious materials. J. Nondestruct. Eval. 2014. [CrossRef]

35. Kogbara, R.B.; Iyengar, S.R.; Grasley, Z.C.; Masad, E.A.; Zollinger, D.G. Non-destructive evaluation of concrete mixtures for direct LNG containment. Mater. Des. 2015, 82, 260-272. [CrossRef]

36. Henry, M.; Darma, I.S.; Sugiyama, T. Analysis of the effect of heating and re-curing on the microstructure of high-strength concrete using X-ray CT. Constr. Build. Mater. 2014, 67, 37-46. [CrossRef] 
37. Chen, W.; Li, Y.; Shen, P.; Shui, Z. Microstructural development of hydrating portland cement paste at early ages investigated with non-destructive methods and numerical simulation. J. Nondestruct. Eval. 2013, 32, 228-237. [CrossRef]

38. Chaix, J.-F.; Garnier, V.; Corneloup, G. Concrete damage evolution analysis by backscattered ultrasonic waves. NDT E Int. 2003, 36, 461-469. [CrossRef]

39. Demčenko, A.; Visser, H.A.; Akkerman, R. Ultrasonic measurements of undamaged concrete layer thickness in a deteriorated concrete structure. NDT E Int. 2016, 77, 63-72. [CrossRef]

40. McCarter, W.J.; Brousseau, R. The, A.C. response of hardened cement paste. Cem. Concr. Res. 1990, 20, 891-900. [CrossRef]

41. Díaz, B.; Nóvoa, X.R.; Pérez, M.C. Study of the chloride diffusion in mortar: A new method of determining diffusion coefficients based on impedance measurements. Cem. Concr. Compos. 2006, 28, 237-245. [CrossRef]

42. Sánchez, I.; López, M.P.; Ortega, J.M.; Climent, M.Á. Impedance spectroscopy: An efficient tool to determine the non-steady-state chloride diffusion coefficient in building materials. Mater. Corros. 2011, 62, 139-145. [CrossRef]

43. Sánchez, I.; Antón, C.; de Vera, G.; Ortega, J.M.; Climent, M.A. Moisture Distribution in partially saturated concrete studied by impedance spectroscopy. J. Nondestruct. Eval. 2013, 32, 362-371. [CrossRef]

44. Sánchez, I.; Nóvoa, X.R.; de Vera, G.; Climent, M.A. Microstructural modifications in Portland cement concrete due to forced ionic migration tests. Study by impedance spectroscopy. Cem. Concr. Res. 2008, 38, 1015-1025. [CrossRef]

45. Ortega, J.M.; Sánchez, I.; Climent, M.A. Impedance spectroscopy study of the effect of environmental conditions in the microstructure development of OPC and slag cement mortars. Arch. Civ. Mech. Eng. 2015, 15, 569-583. [CrossRef]

46. AENOR. UNE-EN 445:2009. Lechadas Para Tendones de Pretensado. Métodos de Ensayo; AENOR: Madrid, Spain, 2009; p. 18.

47. AENOR. UNE-EN 447:2009. Lechadas Para Tendones de Pretensado. Requisitos Básicos; AENOR: Madrid, Spain, 2009; p. 14.

48. Lee, S.T.; Moon, H.Y.; Swamy, R.N. Sulfate attack and role of silica fume in resisting strength loss. Cem. Concr. Compos. 2005, 27, 65-76. [CrossRef]

49. Türker, F.; Aköz, F.; Koral, S.; Yüzer, N. Effects of magnesium sulfate concentration on the sulfate resistance of mortars with and without silica fume. Cem. Concr. Res. 1997, 27, 205-214. [CrossRef]

50. Behfarnia, K.; Farshadfar, O. The effects of pozzolanic binders and polypropylene fibers on durability of SCC to magnesium sulfate attack. Constr. Build. Mater. 2013, 38, 64-71. [CrossRef]

51. Ortega, J.M.; Albaladejo, A.; Pastor, J.L.; Sánchez, I.; Climent, M.A. Influence of using slag cement on the microstructure and durability related properties of cement grouts for micropiles. Constr. Build. Mater. 2013, 38, 84-93. [CrossRef]

52. Pastor, J.L.; Ortega, J.M.; Flor, M.; López, M.P.; Sánchez, I.; Climent, M.A. Microstructure and durability of fly ash cement grouts for micropiles. Constr. Build. Mater. 2016, 117, 47-57. [CrossRef]

53. Ortega, J.M.; Pastor, J.L.; Albaladejo, A.; Sánchez, I.; Climent, M.A. Durability and compressive strength of blast furnace slag-based cement grout for special geotechnical applications. 2014, 64. [CrossRef]

54. AENOR. UNE-EN 196-1:2005. Métodos de Ensayo de Cementos. Parte 1: Determinación de Resistencias Mecánicas; AENOR: Madrid, Spain, 2005.

55. Abadir, M.F.; El Saidy, M.I.; El Sersy, H.H.; Ibrahim, O.A. Estimation of the activation energies in thermal decomposition of some hydrated cement clinker. J. Eng. Appl. Sci. 2006, 53, 815-827.

56. Bernal Camacho, J.; Mahmoud Abdelkader, S.; Reyes Pozo, E.; Moragues Terrades, M. Estudio de la influencia de los medios con presencia de sulfatos en hormigones con cementos sulforresistentes y adiciones minerales. Parte 1: Hormigones expuestos a sulfato sódico $\left(\mathrm{Na}_{2} \mathrm{SO}_{4}\right)$. Rev. Constr. 2013, 12, 14-29. [CrossRef]

57. Gollop, R.S.; Taylor, H.F.W. Microstructural and microanalytical studies of sulfate attack. I. Ordinary portland cement paste. Cem. Concr. Res. 1992, 22, 1027-1038. [CrossRef]

58. Gollop, R.S.; Taylor, H.F.W. Microstructural and microanalytical studies of sulfate attack. IV. Reactions of a slag cement paste with sodium and magnesium sulfate solutions. Cem. Concr. Res. 1996, 26, 1013-1028. [CrossRef]

59. ASTM. Standard Test Method for Length Change of Hydraulic-Cement Mortars Exposed to a Sulfate Solution ASTM C 1012-04; ASTM International: Wesk Conshohocken, PA, USA, 2004; p. 6. 
60. Cabeza, M.; Merino, P.; Miranda, A.; Nóvoa, X.R.; Sanchez, I. Impedance spectroscopy study of hardened Portland cement paste. Cem. Concr. Res. 2002, 32, 881-891. [CrossRef]

61. Climent, M.A.; Ortega, J.M.; Sánchez, I. Cement mortars with fly ash and slag-Study of their microstructure and resistance to salt ingress in different environmental conditions. In Concrete Repair, Rehabilitation and Retrofitting III, Proceedings of the 3rd International Conference on Concrete Repair, Rehabilitation and Retrofitting, ICCRRR2012, Cape Town, South Africa, 3-5 September 2012; CRC Press: Boca Raton, FL, USA; pp. 345-350.

62. Keddam, M.; Takenouti, H.; Nóvoa, X.R.; Andrade, C.; Alonso, C. Impedance measurements on cement paste. Cem. Concr. Res. 1997, 27, 1191-1201. [CrossRef]

63. Barsoukov, E.; Macdonald, J.R. Impedance Spectroscopy; Barsoukov, E., Macdonald, J.R., Eds.; John Wiley \& Sons, Inc.: Hoboken, NJ, USA, 2005.

64. Vladikova, D.; Zoltowski, P.; Makowska, E.; Stoynov, Z. Selectivity study of the differential impedance analysis-Comparison with the complex non-linear least-squares method. Electrochim. Acta 2002, 47, 2943-2951. [CrossRef]

65. Cabeza, M.; Keddam, M.; Nóvoa, X.R.; Sánchez, I.; Takenouti, H. Impedance spectroscopy to characterize the pore structure during the hardening process of Portland cement paste. Electrochim. Acta 2006, 51, 1831-1841. [CrossRef]

66. AENOR. UNE 83987:2014. Durabilidad del Hormigón. Métodos de Ensayo. Determinación de los Coeficientes de Difusión de los Iones Cloruro en el Hormigón Endurecido. Método Multirrégimen; AENOR: Madrid, Spain, 2014; p. 9.

67. Polder, R.; Andrade, C.; Elsener, B.; Vennesland, Ø.; Gulikers, J.; Weidert, R.; Raupach, M. Test methods for on site measurement of resistivity of concrete. Mater. Struct. 2000, 33, 603-611. [CrossRef]

68. Lübeck, A.; Gastaldini, A.L.G.; Barin, D.S.; Siqueira, H.C. Compressive strength and electrical properties of concrete with white Portland cement and blast-furnace slag. Cem. Concr. Compos. 2012, 34, 392-399. [CrossRef]

69. Diamond, S. Aspects of concrete porosity revisited. Cem. Concr. Res. 1999, 29, 1181-1188. [CrossRef]

70. Diamond, S. Mercury porosimetry. Cem. Concr. Res. 2000, 30, 1517-1525. [CrossRef]

71. Palankar, N.; Ravi Shankar, A.U.; Mithun, B.M. Durability studies on eco-friendly concrete mixes incorporating steel slag as coarse aggregates. J. Clean. Prod. 2016, 129, 437-448. [CrossRef]

72. Santhanam, M.; Cohen, M.D.; Olek, J. Mechanism of sulfate attack: A fresh look. Part 2: Proposed mechanisms. Cem. Concr. Res. 2003, 33, 341-346. [CrossRef]

73. El Sokkary, T.; Assal, H.; Kandeel, A. Effect of silica fume or granulated slag on sulphate attack of ordinary portland and alumina cement blend. Ceram. Int. 2004, 30, 133-138. [CrossRef]

74. Çakır, Ö.; Aköz, F. Effect of curing conditions on the mortars with and without GGBFS. Constr. Build. Mater. 2008, 22, 308-314. [CrossRef]

75. Shi, C.; Day, R.L. Acceleration of the reactivity of fly ash by chemical activation. Cem. Concr. Res. 1995, 25, 15-21. [CrossRef]

76. Lee, C.Y.; Lee, H.K.; Lee, K.M. Strength and microstructural characteristics of chemically activated fly ash-cement systems. Cem. Concr. Res. 2003, 33, 425-431. [CrossRef]

77. Leng, F.; Feng, N.; Lu, X. An experimental study on the properties of resistance to diffusion of chloride ions of fly ash and blast furnace slag concrete. Cem. Concr. Res. 2000, 30, 989-992. [CrossRef]

78. Nochaiya, T.; Wongkeo, W.; Chaipanich, A. Utilization of fly ash with silica fume and properties of Portland cement-fly ash-silica fume concrete. Fuel 2010, 89, 768-774. [CrossRef]

79. Chen, J.; Jiang, M.; Zhu, J. Damage evolution in cement mortar due to erosion of sulphate. Corros. Sci. 2008, 50, 2478-2483. [CrossRef]

(C) 2016 by the authors; licensee MDPI, Basel, Switzerland. This article is an open access article distributed under the terms and conditions of the Creative Commons Attribution (CC-BY) license (http:/ / creativecommons.org/licenses/by/4.0/). 